\title{
Acute respiratory distress syndrome: 30 years later
}

Olivier Lesur MD PhD ${ }^{1}$, Yves Berthiaume MD MSc FRCPC ${ }^{2}$, Gilbert Blaise MD FRCPC ${ }^{3}$, Pierre Damas MD ${ }^{4}$, Éric Deland MD FRCPC ${ }^{1}$, Jean-Gilles Guimond MD FRCPC ${ }^{5}$, René $P$ Michel MD FRCPC ${ }^{6}$

${ }^{1}$ Soins Intensifs Médico-Chirurgicaux, Département de Médecine, CUSE Sherbrooke, Sherbrooke; ${ }^{2}$ Centre de Recherche, CHUM, Département de Médecine, Montréal; ${ }^{3}$ Département d'Anesthésie, Pavillon Notre-Dame CHUM, Montréal; ${ }^{4}$ Soins Intensifs Généraux, CHU de Liège, Belgique; ${ }^{5}$ Soins Intensifs Médicaux, Pavillon Notre-Dame CHUM, Montréal; ${ }^{6}$ Department of Pathology, Lyman Duff Medical Sciences Building, McGill University, Montréal, Quebec

O Lesur, Y Berthiaume, G Blaise, et al. Acute respiratory distress syndrome: 30 years later. Can Respir J 1999;6(1):71-86.

Acute respiratory distress syndrome (ARDS) was first described about 30 years ago. Modern definitions and statements have recently been proposed to describe ARDS accurately, but none is perfect. Diffuse alveolar damage is the basic pathological pattern most commonly observed in ARDS, and the term includes permeability edema. The alveolar epithelium of the alveolar-capillary barrier is clearly a key component requiring repair, given its multipotent functional activity. Lung inflammation and neutrophil accumulation are essential markers of disease in ARDS, and a wide variety of pro- and anti-inflammatory cytokines have been described in the alveolar fluid and blood of patients. These molecules still have to prove their value as diagnostic or prognostic biomarkers of ARDS.

Supportive therapy in ARDS improved in the past decade; mechanical ventilation with lung protective strategies and patient positioning are gaining interest, but the indications for corticosteroids for ARDS are still debated. Nitric oxide may have a place in the treatment of one-third of patients.
Novel approaches, such as surfactant replacement and liquid ventilation, may further improve supportive therapy. Innovative interventions may be on the horizon in treatments that help to resolve or modulate common pathways of ARDS, such as inflammation (eg, granulocyte-colony stimulating factor) or epithelial repair (eg, keratinocyte growth factor).

Key Words: Acute lung injury, Corticosteroids, Epithelial repair, Inflammation, Liquid ventilation, Mechanical ventilation, Neutrophils, Nitric oxide (NO), Patient positioning, Permeability edema, Surfactant

\section{Syndrome de détrese respiratoire aiguë de} l'adulter : 30 ans plus tard

RÉSUMÉ : Le syndrome de détresse respiratoire aiguë de l'adulte (SDRA) a été décrit comme une entité il y a 30 ans. Plusieurs définitions et mises au point actualisées ont été proposées, mais aucune n'est parfaite. Le dommage alvéolaire diffus est l'altération pathologique de base observée dans le SDRA, et inclut un oedème de perméabilité traduisant l'altération de la barrière alvéolo-capillaire. L'épithélium alvéolaire est clairement un composant-clé de cette barrière de par son activité fonctionnelle pluripotente, et doit être réparé.

voir page suivante

This work is a summary of an international symposium held in Sherbrooke, Québec in October 1997

Correspondence and reprints: Dr O Lesur, Groupe de Recherche en Pathophysiologie Respiratoire, Centre de Recherche Clinique, 3001, 12ème Avenue Nord, CUSE Sherbrooke, Quebec J1H 5N4. Telephone 819-346 1110 ext 14881, fax 819-564 5377,

e-mailolesur@courrier.usherb.ca 
L'inflammation pulmonaire avec accumulation de polynucléaires neutrophiles est un marqueur essentiel du SDRA, et une grande variété de cytokines pro- et anti-inflammatoires a été identifiée dans les liquides alvéolaires et le sang des patients atteints de SDRA. Ces molécules ont encore à faire la preuve de leur valeur diagnostique et pronostique comme biomarqueurs du SDRA. Le traitement de support du SDRA s'est amélioré depuis 10 ans. La ventilation mécanique avec stratégie de protection pulmonaire et l'utilisation du procubi- tus suscitent beaucoup d'intérêts, les indications tardives des corticostéroïdes dans le SDRA sont encore débattues, le NO a probablement sa place dans l'algorythme thérapeutique chez $1 / 3$ des patients. Les nouvelles approches comme l'instillation de surfactant et la ventilation liquide pourraient encore améliorer la thérapie de support. Les interventions innovantes pourraient venir de traitements visant à moduler ou mieux combattre des voies communes à tous les SDRA comme l'inflammation (eg, G-CSF) ou la réparation épithéliale (eg, KGF).

\section{Outline}

What underlies acute respiratory distress syndrome? E Deland

Pathology of ARDS: Importance of edema RP Michel

Epithelial alteration and repair in ARDS: A key issue O Lesur

Inflammation and neutrophils in ARDS: A double-edged sword P Damas

\section{Therapeutic modalities in ARDS: Reaching a consensus and being innovative JG Guimond, G Blaise, Y Berthiaume}

\section{WHAT UNDERLIES ACUTE RESPIRATORY DISTRESS SYNDROME?}

More than 30 years ago, Ashbaugh and coworkers $(1,2)$ coined the term 'acute respiratory distress' to designate acute hypoxemic respiratory failure due to noncardiogenic pulmonary edema, complicating the course of severe medical or surgical illnesses. Since then, acute respiratory distress syndrome (ARDS) has been recognized worldwide as a relatively frequent complication of a variety of medical and sur-

\section{TABLE 1}

Conditions that can provoke acute lung injury and acute respiratory distress syndrome

\begin{tabular}{l} 
Direct pulmonary insults \\
Aspiration of gastric contents \\
Pulmonary infections \\
Viral \\
Bacterial \\
Pneumocystis carinii \\
Near-drowning \\
Toxic gas or fume inhalation \\
Pulmonary contusions \\
Indirect pulmonary insults \\
Recovery from severe shock \\
Sepsis from extrapulmonary infections \\
Severe extrathoracic trauma \\
Multiple blood transfusions \\
Severe, extensive burns \\
Severe pancreatitis \\
\hline
\end{tabular}

gical conditions (Table 1), and intensive care practitioners regularly face this difficult problem in patient care. Consequently, the syndrome has generated intense interest in the biomedical sciences, and considerable fundamental and clinical research efforts have been devoted to improve the understanding of ARDS and how it should be treated. Despite these efforts, a satisfactory, unequivocal definition of the syndrome has not been found (3-6). Criteria used in diagnosing ARDS have differed widely in many reports and studies, resulting in considerable variations in the reported incidence rates (7) and case-fatality ratios (8).

In 1992, a statement proposing clinical criteria for the diagnosis of ARDS emerged from the American-European Consensus Conference on ARDS (EACC), held by the American Thoracic Society and the European Society of Intensive Care Medicine $(9,10)$. This definition of ARDS is an operational one, based on a set of four simple clinical criteria. The EACC also proposed criteria defining acute lung injury (ALI), a similar, but presumably less severe, form of acute pulmonary injury resulting from identical causes (Table 2). Although these definitions have the merit of simplicity and practicality, and should guide the inclusion of patients in clinical studies of the syndrome, many uncertainties remain regarding on the fundamental nature of the syndrome and how to achieve optimal precision in diagnosis (11). Whether the proposed distinction between ALI and ARDS will be of significant utility in either patient care or clinical trials also remains to be demonstrated.

What is ARDS?: ARDS is considered to be ".... a syndrome of inflammation and increased (alveolar-capillary wall) permeability...acute in onset and persistent - lasting days to weeks -...associated with one or more known risk factors... characterized by arterial hypoxemia...and diffuse pulmonary infiltrates [resulting from]...injury to the lung epithelium and the lung endothelium..." (9). Central to this definition of ARDS is the concept of diffuse alveolar damage (DAD), a widespread disruption of the alveolocapillary barrier's integrity, caused by an acute insult, originating either from the airways or from the systemic circulation. Type I epithelial cells (or pneumocytes), which cover more than $90 \%$ of the alveolar epithelial surface, and type II epithelial cells, which lie at the corner of distal airspaces, are critical anatomical determinants of alveolar permeability to fluid and proteins (Figure 1) (12). These cells show the earliest morphological changes consistent with injury in the lungs of patients with ARDS. Thus, early injury of sensitive type I epithelial cells 
TABLE 2

American-European Consensus Conference criteria for diagnosing acute lung injury and acute respiratory distress syndrome (9)

\begin{tabular}{lcc}
\hline & Acute lung injury & Acute respiratory distress syndrome \\
\hline $\begin{array}{l}\text { Onset* } \\
\begin{array}{l}\text { Ratio of partial pressure of arterial oxygen to } \\
\text { fraction of inspired oxygen }\end{array}\end{array}$ & Acute & Acute \\
$\begin{array}{l}\text { Aspect of the chest radiograph (frontal view) } \\
\text { Pulmonary artery wedge pressure }\end{array}$ & Less than $300 \mathrm{mmHg}$ & Less than $200 \mathrm{mmHg}$ \\
\hline
\end{tabular}

*The American-European Consensus conference statement gives precise time limits (time lapse between risk factor[s] and onset) that are compatible with the term 'acute'; 'If a pulmonary artery catheter is not used, clinical evidence that left atrial hypertension is absent is sufficient. Data from reference 9

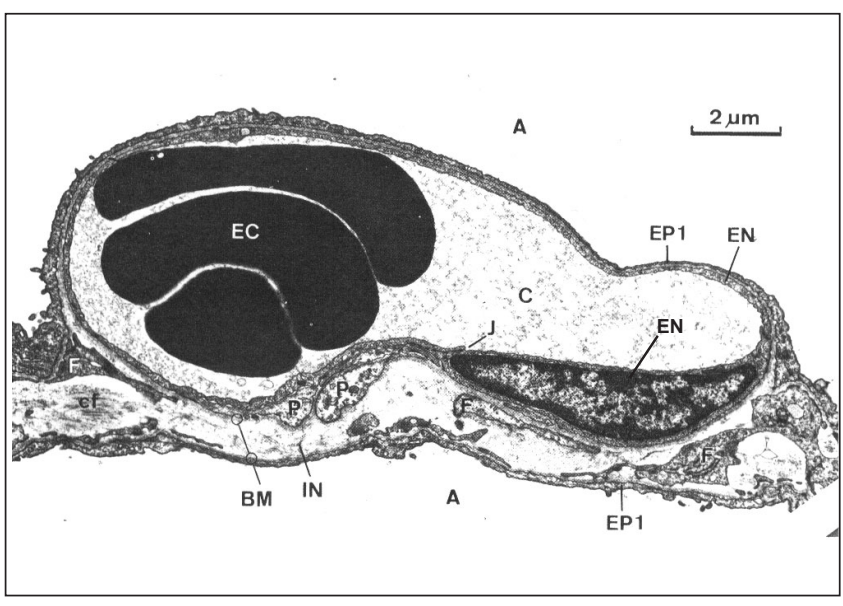

Figure 1) Structural determinants of alveolocapillary wall permeability in the normal human lung. At its thinnest portion, where gas exchanges occur, the alveolocapillary wall is formed by very thin cytoplasmic extensions of both the capillary endothelial cell and the alveolar epithelial cell (type I alveolar epithelial cell [pneumocyte]), resting on each side of a common basement membrane. Integrity of type I alveolar epithelial cells, which cover $95 \%$ of the alveolar surface, is essential to the maintenance of fluid and protein permeability within physiological limits. These cells are also uniquely susceptible to injury because of their relatively large surface area and their low self-regenerative capacities. Retraction and desquamation of type I pneumocytes are the earliest morphological findings in acute respiratory distress syndrome. A Alveolar lumen; BM Basement membrane; C Capillary lumen; EC Erythrocytes; EN Capillary endothelial cell; EP1 Type I epithelial cell; IN Alveolar wall intersitium; $J$ Endothelial cell intercellular junction. Adapted with permission from reference 12

best accounts for the abrupt increase in permeability of the alveolocapillary wall seen in ARDS (13). The loss of barrier integrity associated with DAD provokes the flooding of alveoli with exudative, protein-rich edema and subsequent deposition of proteinacious material (hyaline membranes), the latter probably being related to the preferential resorption of water and electrolytes compared with proteins with higher molecular weights (14).

In some patients, less severe degrees of DAD allow fairly rapid restoration of normal epithelial function, reabsorption of pulmonary edema and recovery from respiratory failure within a few days $(15,16)$. Other patients experience severe anatomical disruption of the alveolar-capillary interface,

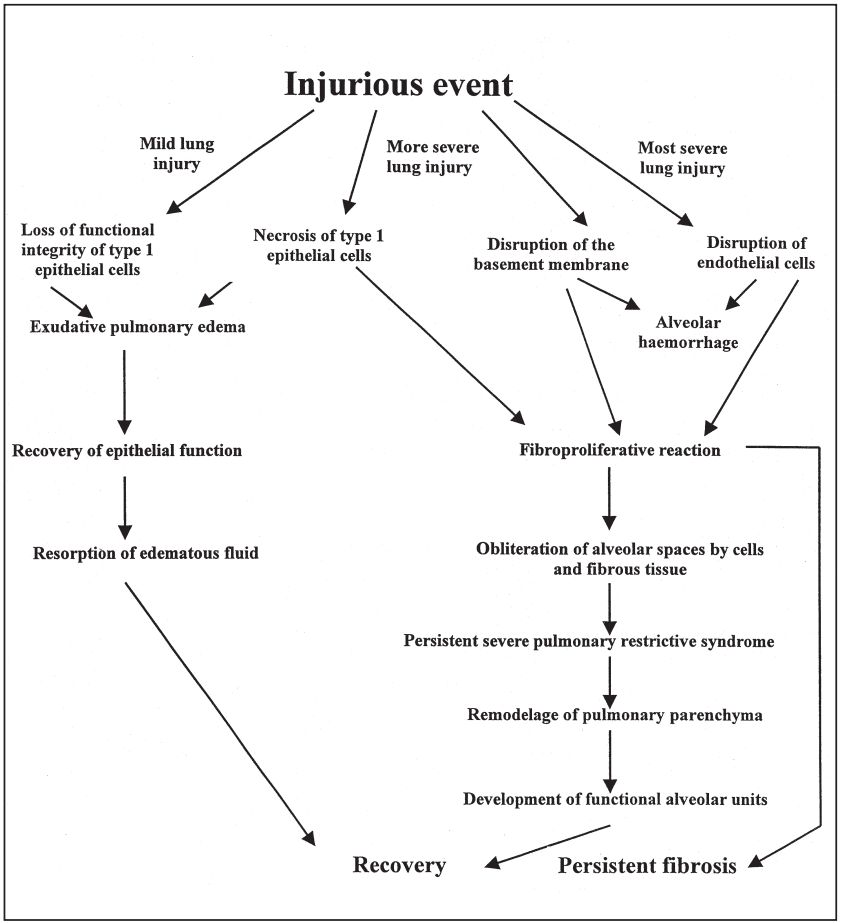

Figure 2) Representation of the various phases in the evolution of acute respiratory distress syndrome. Recovery of sufficient gas exchange to allow withdrawal from mechanical ventilation is critically dependent on severity of the initial pulmonary insult. In the most favourable cases, mild parenchymal damage allows the recovery of sufficient respiratory function within a few days. In the most severe cases, extensive damage provokes an intense fibroproliferative response that either resolves after many weeks of ventilator dependency or remains unresolved with persistent fibrosis

with necrosis of type I epithelial cells and denudation of the underlying basement membrane. In the severest cases, basement membrane disruption and even complete destruction of the alveolocapillary wall can lead to alveolar hemorrhage and can be followed by an intense proliferative response by type II epithelial cells and fibroblasts with pulmonary fibrosis after a few days. This fibroproliferative response provokes persistent alveolar consolidation, impaired gas exchange and a severely restrictive pattern on pulmonary function, even after resolution of the edematous phase $(13,17)$. Patient dependency on mechanical ventilation can consequently be prolonged for many weeks or more. Patients who survive this period of prolonged ventilator dependency 


\section{TABLE 3}

\section{Various pulmonary disorders that can mimic acute} respiratory distress syndrome (ARDS)*

- Allergic alveolitis

- Bronchiolitis obliterans organizing pneumonia

- Eosinophilic pneumonia

- Idiopathic interstitial pneumonitis

- Immune alveolar hemorrhage

- Pulmonary vasculitis

- Pulmonary lymphoma

- Lymphangitic carcinomatosis

- Bronchioloalveolar cell carcinoma

*These diseases can produce hypoxemia and radiographic patterns consistent with American-European Consensus Conference criteria. In a patient developing hypoxemia and diffuse pulmonary infiltrates, the absence of exposure to a recognized risk factor for ARDS should prompt the clinician to consider these alternatvie diagnoses
TABLE 4

Etiologies of permeability edema

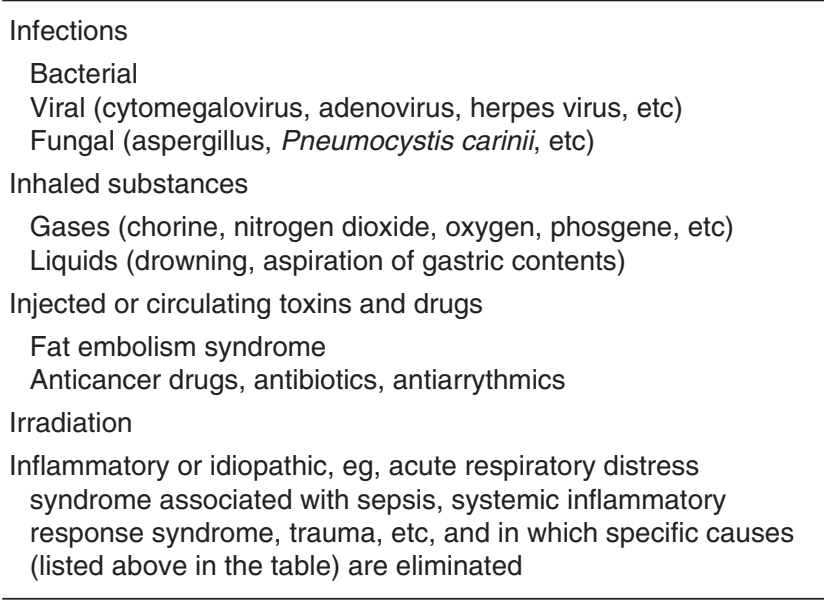

may be similar, profound clinically relevant differences in pathophysiology undoubtedly exist. A rational subdivision of the syndrome based on pathophysiological considerations would be most useful in devising clinical research strategies because the different forms of ARDS may not respond equally to similar therapeutic interventions. For instance, Pneumocystis carinii pneumonia in acquired immunodeficency syndrome patients, unlike other infectious causes of ARDS, is remarkable for its excellent response to early systemic corticosteroid therapy (25), which must reflect a unique sequence of events linking it to ARDS. Unfortunately, in pneumocystis pneumonia, as with other causes of ARDS, knowledge of the underlying pathophysiology is too fragmentary to allow a rational classification of the syndrome. In the absence of such a classification, clinical studies evaluating therapies specifically aimed at modifying the course of ARDS should ideally include patients with similar causes of lung injury, failing this, a subset of patients responding to a given form of therapy may escape notice, masked by groups of nonresponding patients.

\section{PATHOLOGY OF ARDS: IMPORTANCE OF EDEMA}

To understand pulmonary edema, it is useful to consider the 'Starling equation'. Although the concepts of fluid exchange across vascular walls were indeed enunciated by Starling in 1896, there is no actual equation in his publication; rather, subsequent authors and investigators designed and refined different variants. One frequent version is:

$$
\dot{Q} f=K f\left[(P m v-P i s)-\sigma\left(\pi_{m v}-\pi_{i s}\right)\right]
$$

in which $\dot{Q}$ is net fluid filtration rate out of the vasculature $(\mathrm{mL} / \mathrm{min}), \mathrm{Kf}$ is the fluid filtration coefficient, a measure of vascular permeability to fluid and vascular surface area (approximately $0.2 \mathrm{~mL} / \mathrm{min} / 100 \mathrm{~g} / \mathrm{mmHg}$ ); Pmv is microvascular (capillary) pressure (approximately $10 \mathrm{mmHg}$ ), Pis is the interstitial pressure (approximately $-5 \mathrm{mmHg}$ ), $\sigma$ is the os- 
TABLE 5

Contrasting pathobiology of hydrostatic pulmonary edema and acute respiratory distress syndrome (ARDS)

\begin{tabular}{|c|c|c|}
\hline Parameter & Hydrostatic edema & Permeability edema (ARDS) \\
\hline Etiology and pathogenesis & $\begin{array}{l}\text { Elevated microvascular pressure, normal } \\
\text { endothelial epithelium }\end{array}$ & $\begin{array}{l}\text { Elevated microvascular permeability due to } \\
\text { damage of endothelium and epithelium by } \\
\text { cytokines, neutrophils, etc }\end{array}$ \\
\hline Fluid protein content & Low versus plasma, due to sieving & High, with fibrin \\
\hline Sequence of fluid accumulation & $\begin{array}{l}\text { Orderly: congestion, interstitial edema, then } \\
\text { alveolar edema }\end{array}$ & $\begin{array}{l}\text { Prominent alveolar flooding, less interstitial } \\
\text { edema }\end{array}$ \\
\hline Macroscopy/radiography & Perihilar edema, frothy & $\begin{array}{l}\text { Consolidated, diffuse with or without } \\
\text { pneumonia, emboli }\end{array}$ \\
\hline Light microscopy & $\begin{array}{l}\text { Prominent congestion, less alveolar edema } \\
\text { (low protein) }\end{array}$ & $\begin{array}{l}\text { Hyaline membranes, thick alveolar edema } \\
\text { inflammatory cells, with or without emboli }\end{array}$ \\
\hline Electron microscopy & Normal endothelium, epithelium & $\begin{array}{l}\text { Endothelial and epithelial blebbing, disruption, } \\
\text { inflammatory cells in interstitium }\end{array}$ \\
\hline Chronic effects & Very mild fibrosis and 'brown induration' & Can lead to severe diffuse pulmonary fibrosis \\
\hline
\end{tabular}

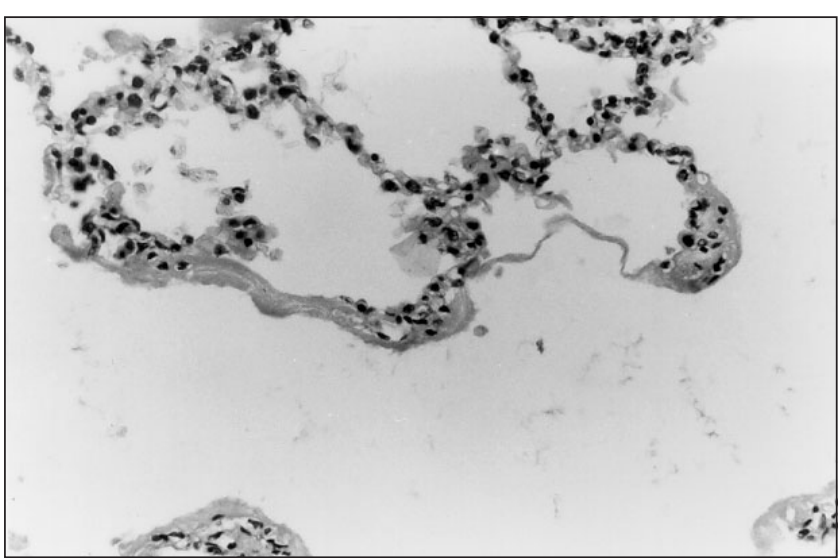

Figure 3) Photomicrograph of exudative stage of acute respiratory distress syndrome (three to 10 days) with hyaline membranes lining the alveolar duct and alveoli. There are also traces of proteinaceous edema fluid in the centre of the alveoli. Hematoxylin and eosin, original magnification $\times 100$

motic reflection coefficient that determines the relative contribution of the oncotic pressure gradient across the vasculature to the net driving pressure and is a measure of the permeability of a given membrane (eg, endothelial) to a given solute (eg, albumin) (it varies between 0 when the membrane is totally permeable and 1 when it is impermeable; in the lung, $\sigma$ is approximately 0.75 to 0.80$) ; \pi \mathrm{mv}$ is the oncotic pressure of the blood in the microvasculature of the lung (approximately $24 \mathrm{mmHg}$ ) and $\pi$ is is the oncotic pressure in the pulmonary interstitium (approximately $14 \mathrm{mmHg}$ ). Edema occurs when Qf rises to a point where the lymphatics can no longer handle the filtered fluid.

Permeability edema occurs due to increased $\mathrm{Kf}$ and/or reduced $\sigma$, and is best classified according to etiology. ARDS can be defined in a wide sense (26) and encompasses most of the forms of permeability edema whose etiologies are detailed in Table 4, or in a restrictive sense as the syndrome that accompanies sepsis, the systemic inflammatory response syndrome (SIRS) and severe trauma.

The pathological abnormalities of ARDS arise from the damage inflicted to the lungs and the subsequent cascade of

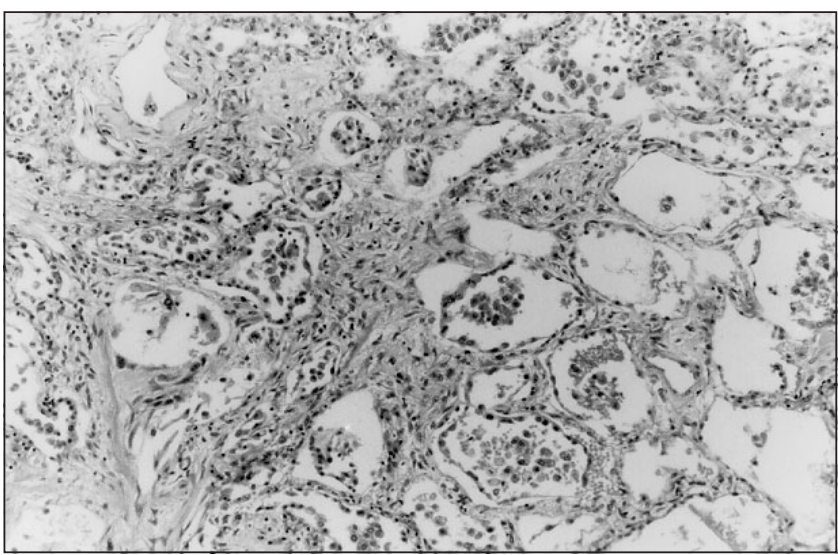

Figure 4) Medium power photomicrograph of proliferative stage of acute respiratory distress syndrome (two to three weeks) with obliteration of the structure of the lung, replaced by rearranged airspaces separated by granulation tissue and fibrosis. Hematoxylin and eosin, original magnification $\times 100$

pathogenetic events, resulting in an elevation of pulmonary microvascular permeability, and differ substantially from those observed in hydrostatic edema (Table 5). The alterations in ARDS can be divided into those general to ARDS and several forms of permeability edema, and those reflecting a specific etiology. As indicated above, the general alterations are encompassed by the term DAD, and are separated into acute exudative and chronic proliferative phases (26-29).

In the acute phase, the lungs are heavy (at least twice normal), red and indurated, with frequent secondary findings such as pneumonia and thromboemboli. By light microscopy, there is prominent protein-rich alveolar edema forming 'hyaline membranes', mainly composed of necrotic type I epithelial cells, fibrin and other plasma proteins that line alveoli, alveolar ducts and respiratory bronchioles (Figure 3). Interstitial edema is also seen, although it is often less prominent than in hydrostatic edema, primarily because the alveolar phase predominates or occurs more rapidly due to the epithelial damage (30). By electron microscopy, there is blebbing and damage to endothelial and epithelial cells, and 


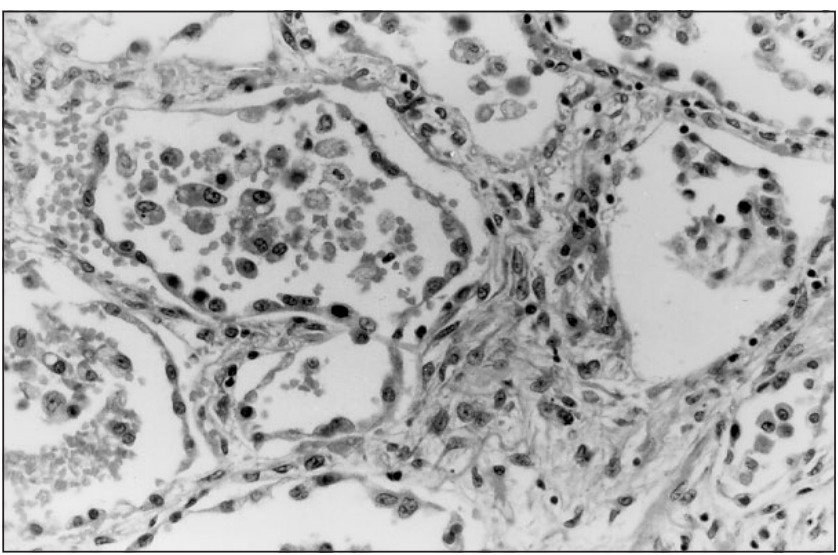

Figure 5) Higher power photomicrograph of same proliferative stage of acute respiratory distress syndrome showing alveolar spaces lined by proliferating type II epithelial cells (pneumocytes), separated by fibrosis with proliferating fibroblasts. Hematoxylin and eosin, original magnification $\times 250$

neutrophils, erythrocytes and platelets are frequently seen between them entering the interstitium (13).

In the chronic proliferative phase (about five to seven days and beyond), if resolution has not occurred, the macroscopic picture of pulmonary fibrosis ensues, with reorganization of alveoli into large spaces separated by indurated, dense connective tissue; when advanced, a 'honeycomb' pattern results in which the reorganized spaces are 3 to $12 \mathrm{~mm}$ in diameter, and visible on chest radiographs and on high resolution computed tomographic (CT) scan (Figure 4). By light microscopy, there is destruction and collapse of normal alveoli, replaced by larger simplified spaces lined by hyperplastic type II epithelial cells and separated by thick walls of connective tissue with fibroblasts, collagen, extracellular matrix and inflammatory cells (Figure 5).

In addition to these general pathological alterations of DAD in ARDS, several of the etiologies of permeability edema have more specific, recognizable changes upon microscopic examination or by other methods. For example, in the infectious causes, bacterial pneumomias that cause a picture of ARDS are identifiable by culture; Pneumocystis carinii is visualized by light microscopy of bronchoalveolar lavage fluid or lung biopsies using the silver methenamine stain. In aspiration pneumonia, the aspirated material can be identified by light microscopy and is frequently associated with a foreign body giant cell reaction. In fat embolism, fat globules are seen in capillaries, giving them an empty appearance devoid of erythrocytes. Some of the drug reactions may also produce specific changes, eg, following amiodarone in which numerous foamy macrophages fill the alveoli.

Mechanical ventilation, with or without positive endexpiratory pressure (PEEP), appears to reduce alveolar edema and ameliorate gas exchange by at least two mechanisms, the first by opening and maintaining open the alveoli, and the second by redistributing the liquid from the alveolar spaces to the interstitium (31-33). Nevertheless, mechanical ventilation has significant disadvantages, particularly when large volumes of air are used; several studies have shown that

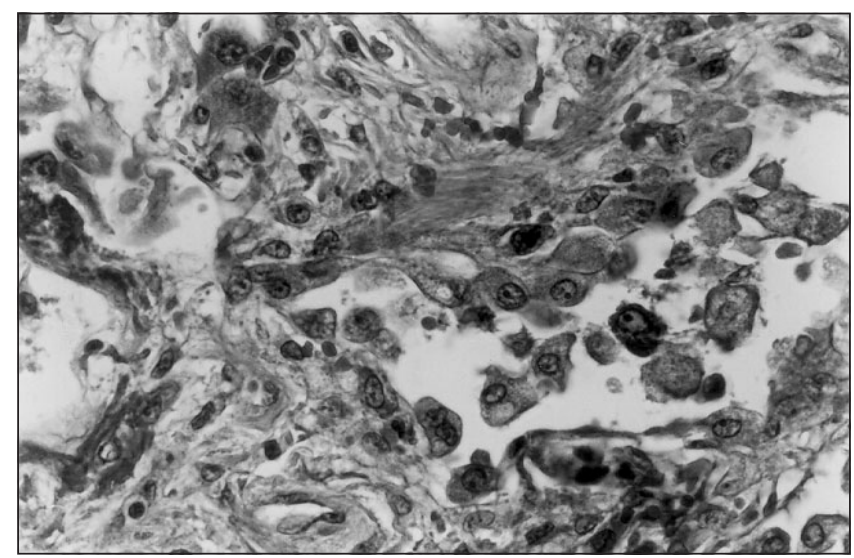

Figure 6) Hypertrophic, hyperpastic and cuboidal metaplasic epithelial cells in a lung distal airspace of organizing phase of acute respiratory distress syndrome. Masson's trichrome, original magnification $\times 400$

the latter produces significant injury to pulmonary endothelial cells, with resulting permeability edema (34).

ARDS is an important cause of permeability pulmonary edema with both specific and nonspecific etiologies, some of which are readily recognized by pathological examination. One of the factors associated with a poor prognosis in ARDS is the progression to the proliferative stage resulting in diffuse pulmonary fibrosis, and one of the challenges is to identify the mediators and determinants resulting in this ominous complication. Among factors that determine whether ARDS resolves or progresses to fibrosis is whether the alveolar basement membrane is damaged $(35,36)$. One study showed that the laminin in this basement membrane disappears first in ARDS, whereas 7S and type IV collagen disappear later in the exudative phase, reappearing in the proliferative phase (37). Thus, continued investigation of the cellular and molecular events that mediate this progression, particularly in humans, is important.

\section{EPITHELIAL ALTERATION AND REPAIR IN ARDS: A KEY ISSUE}

As indicated above, the pathology of ALI is characterized by DAD, separated into an 'exudative phase' characterized by extensive epithelial and endothelial injury, inflammation, edema, and the accumulation of fibrinous exudates in airspaces. Subsequently either complete restoration or a 'proliferative/organizing phase' characterized by alveolar and bronchiolar epithelial cell regeneration, and varying degrees of intra-alveolar or interstitial fibrosis (25-28) occur.

Most research into ALI and ARDS has addressed mechanisms of lung injury with much less emphasis on the reparative processes. However, the balance between the rate and quality of epithelial repopulation and the extent of fibrosis is a major factor that determines the outcome in ALI, as outlined in the works of Adamson et al (38-40), and recently reviewed by Berthiaume and Lesur (41). Although alveolar and vascular spaces are the most recognized and studied targets of ALI because of the direct impact of noxious agents on 
gas exchange, small airways from the respiratory bronchioles to alveolar ducts are almost constantly altered as well. Hypertrophic and hyperplastic alveolar type II epithelial cells, together with metaplasic cuboidal or columnar cells, and a prominent fibrosis are generally observed in the organizing phase of ALI, producing the typical honeycomb pattern (Figure 6). The stem cells producing these metaplastic epithelial alterations, although still debated, may orginate from type II epithelial cells or migrating distal respiratory bronchiolar cells (hence the term 'alveolar bronchiolization') (42).

Critical molecular events involved in the control and optimization of lung repair are not completely identified. However, the major steps necessary for recovery to occur are the removal of cell debris, fibrin degradation products and edema; repair of the basement membrane; control of fibroblast migration, growth and collagen production; re-establishment of the air-blood interface; and stabilization of surfactant metabolism. Complete re-establishment of the alveolar side of the air-blood interface requires that type II epithelial cells migrate and proliferate rapidly, but also that they differentiate into type I epithelial cells to restore a phenotypically preserved normal distal airspace epithelium and control apoptosis (or programmed cell death) $(41,43)$.

ALI can simply resolve with specific treatments (eg, antibiotics), but when the criteria of ARDS (which are broad and

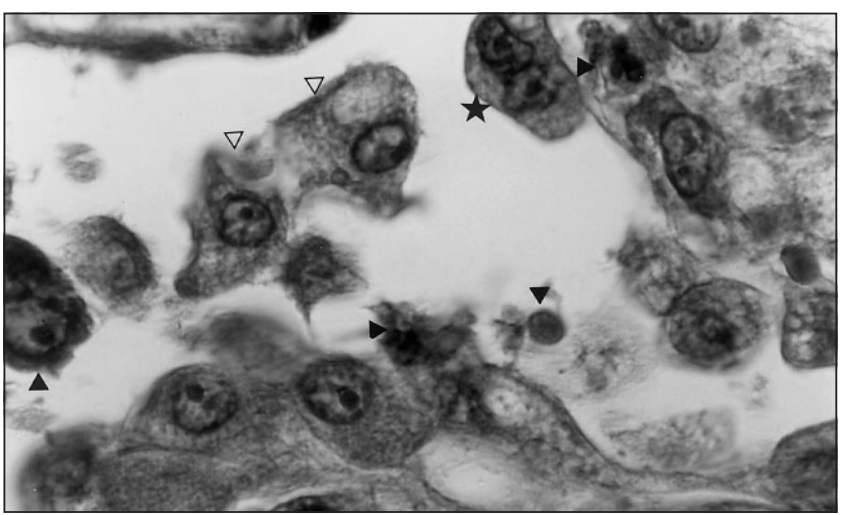

Figure 7) Higher magnification of Figure 6 focusing on distal epithelial alterations in acute respiratory distress syndrome. Of note, associated features of knobby, hypertrophic, hyperplastic (see diploid cell $\star$ ), evidently metaplastic epithelial cells in the airspace. Some of these cells are shed from basal membrane $(\Delta)$ and apoptotic processes are ongoing in others $(\mathbf{\Delta})$. Masson's trichrome $\times 1000$

controversial as discussed above) are met, its mortality can reach as much as $40 \%$ to $60 \%$, with about 70,000 to 125,000 North Americans dying from it each year $(44,45)$. These figures are extremely disappointing in view of 30 years of improved supporting treatments in intensive care units (ICUs) and despite a better understanding of risk factors. During the

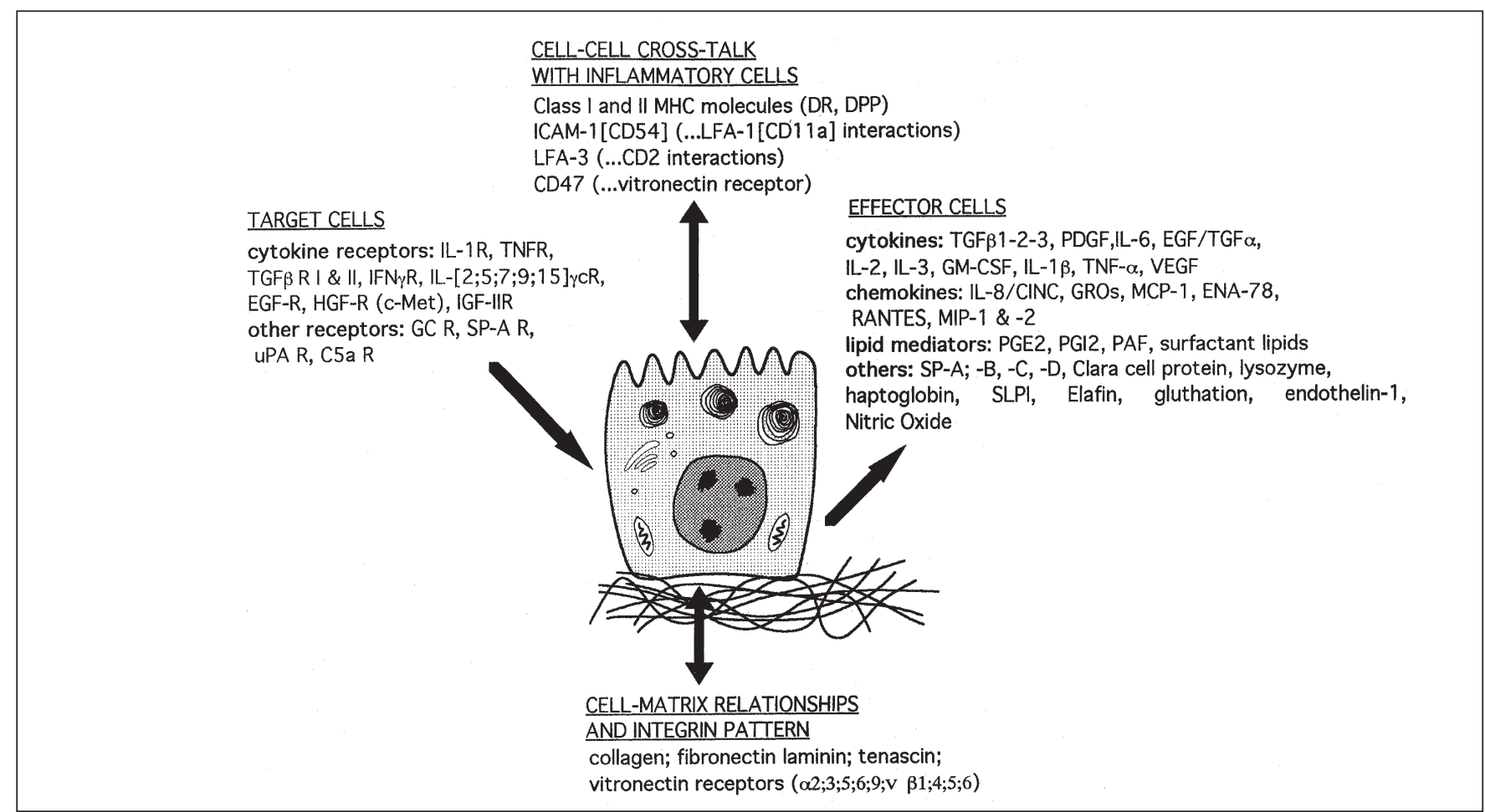

Figure 8) Cross-talking pluripotent alveolar epithelial cell in the deep lung. C5aR Complement 5 a receptor; CINC Cytokine-induced neutrophil chemoattractant; EGF Epidermal growth factor; ENA Epithelial-derived neutrophil activation factor; $\gamma c R$ Gamma chain receptor; GC Glucocorticoid; GM-CSF Granulocyte macrophage-colony stimulating factor; GROs Growth-related proteins; HGFR Hepatocyte growth factor receptor; ICAM-1 Intercellular adhesion molecule-1; IFN- $\gamma$ R Interferon-gamma receptor; IGF-IIR insuline growth factor-II receptor; IL Interleukin; LFA Lymphocyte function associated antigen; MCP Monocyte chemotactic protein; MHC Major histocompatibility complex; MIP Macrophage inflammatory protein; PAF Platelet activating factor; PDGF Platelet-derived growth factor; PG Prostoglandins; R Receptor; RANTES Regulated on activation normal T expressed and secreted; SLPI Secretory leukocyte protease inhibitor; SP Surfactantassociated proteins; TGF Transforming growth factor; TNF Tumour necrosis factor; uPA R Urokinase plasminogen activator receptor; VEGF Vascular endothelial growth factor 
past decade, several large multicentre studies aimed at identifying the prognostic factors of ARDS have been published. It is clear, however, that apart from avoiding already known risk factors whenever possible, no definite effective predictive factors have been recognized (46).

Restitution of an intact alveolar epithelium is certainly a first-line approach in repair following lung injury. Adamson et al (38-40) have stressed this issue in the past 25 years and have clearly demonstrated that restoration of epithelialmesenchymal interactions is crucial to ensure healing without fibrosis. Epithelial repair includes several events such as adhesion, spreading, migration, proliferation and differentiation (Figure 7). These activities must be properly timed and coordinated to allow restoration before fibrosis and irreversible epithelial metaplasia take place, as observed in interstital pulmonary fibrosis (41).

The alveolar epithelium exhibits numerous functions that must be restored following ARDS for the lung to recover. It exchanges gas and liquids with the blood stream and generates surfactant that reduces surface tension. It is also antiinflammatory and immunosuppressive. It clears the airspaces of water and electrolytes by expressing several pumps, such as aquaporins, epithelial sodium channels and sodiumpotassium-ATPase. It is a scavenger of fibrin and a major producer of antioxidants and protease inhibitors. It is a cellular target for complex but essential cross-talk (Figure 8). The environmental requirement to promote resurfacing and repair in ARDS is composed of provisional matrix containing basal membrane material, and the alveolar epithelium must interact with it by synthesizing its own proteins and by expressing a large panel of specific integrins (Figure 8).

Several cytokines are major promoters of epithelial repair in the lung. Heparin sulphate-binding proteins (eg, epidermal growth factor-tumour growth factor [TGF], keratinocyte growth factor [KGF], human growth factor and acidic fibroblast growth factor are paracrine fibroblast-derived polypeptides capable of supporting proliferation and migration/adhesion of alveolar epithelial cells (47). TGF $\beta$ s are important regulators (46) and platelet-derived growth factor is the putative but potentially harmful modulator of wound healing in view of its role in pulmonary fibrosis (48-50). The lymphokines and monokines interleukin (IL)-2, IL-15, interferongamma and related molecules may have a heretofore unsuspected role in epithelial repair by promoting migration and controlling apoptosis $(51,52)$.

Treatment of ARDS aimed at improving epithelial repair is possible by delivering cytokines either in situ or systemically or by a combination of both. Clearly, additional experimental data are required before planning clinical trials, but this issue may be resolved in the near future.

\section{INFLAMMATION AND NEUTROPHILS IN ARDS: A TWO-EDGED SWORD}

At the beginning of the 1980s, neutrophils were thought to play a central role in lung injury, particularly following their activation by the complement system and/or by arachidonic acid derivatives, such as protaglandins, thromboxanes and leukotrienes. Morphological studies from patients dying from ARDS demonstrated that neutrophils were present in the lower respiratory tract, adhering to endothelium, invading the interstitium and filling the alveoli. Animal models of ALI have also implicated the neutrophil as an important player, with some studies showing that drug-induced neutropenia decreased its severity. However, studies on humans seeking specific markers of severity or prognosis (that may or not involve neutrophils) in the serum or plasma of patients at risk of or suffering from ARDS were frequently disappointing. Bronchoalveolar lavage (BAL), by providing direct access to distal airspaces, has significantly facilitated progress in the understanding of the natural history of ARDS.

In 1986, Weiland et al (53) observed that in 11 patients, studied within $24 \mathrm{~h}$ of ICU admission with ARDS, neutrophils comprised $67 \%$ of the cells in BAL fluid, whereas in mechanically ventilated patients without ARDS or in normal volunteers, they accounted for only $4 \%$ and $0.8 \%$, respectively. Neutrophil counts were also positively correlated with the protein levels in BAL fluid and the severity of gas exchange abnormalities. To emphasize the role of these cells further, Weiland et al (53) reported that BAL fluid contained significant levels of neutrophil enzymes such as elastase (although inactivated by binding to alpha1-antiproteinase inhibitor) and especially myeloperoxidase. In contrast, Fowler et al (54) reported that patients with sepsis or aspiration who were at risk to develop ARDS but failed to meet its criteria,had BAL fluid neutrophil counts similar to those with true ARDS. This observation has been confirmed by others. In 1994, Steinberg et al (55) studied the evolution of different cell populations in BAL fluids in 125 ARDS patients sampled on days 3, 7 and 14 after the onset of ARDS. This study distinguished ARDS following sepsis, major trauma or other causes such as aspiration, multiple transfusion or drug overdose. A significantly greater and more sustained neutrophil count was observed in patients who died than in those who survived, especially in the septic group. Moreover, it is noteworthy that in all these groups of patients, survivors exhibited a progressive rise in the number of macrophages, whether expressed as a percentage or in absolute numbers; on day 14 of their course, their macrophage levels were higher in survivors than in nonsurvivors. The question arises whether these cells play a beneficial role in the resolution of ALI. This possibility must be balanced against the notion that these cells are also believed to act as first responders and as producers of proinflammatory cytokines. This issue remains unresolved.

To account for the invasion of the alveolar space by neutrophils, chemoattractive agents have been sought. IL-8 produced by several cell types including macrophages, neutrophils, fibroblasts and endothelial cells is one of the most potent chemoattractants for neutrophils. In 1992, Miller et al (56) studied 19 patients with ARDS and found that those who died had significantly higher IL-8 concentrations in their BAL fluids than the survivors, and that there was a correlation between the percentage of neutrophils in the BAL fluid and IL-8 concentration. However, Jorens et al (57), also in 
1992, reported that IL-8 levels in BAL fluids in 15 ARDS patients were not statistically different from those obtained in BAL fluids from patients after cardiac surgery who did not go on to develop ARDS. In 1996, Miller et al (58) showed that IL-8 levels were statistically higher in BAL specimens from septic ARDS patients than in those from ARDS patients without sepsis. The role of other chemoattractant molecules has also been investigated. Goodman et al (59) studied the relationship between BAL fluid cell population and the concentration of two neutrophil chemoattractants: IL-8; the epithelial cell-derived neutrophil activator-78; and two potent monocyte chemoattractants, monocyte chemomonocyte chemotactic peptidetactic peptide (MCP-1) and macrophage inflammatory peptide 1 . All these cytokines were significantly increased regardless of the duration of ARDS. The amounts of the two neutrophil attractants were independently correlated with neutrophil counts but not with outcome, whereas only MCP-1 was directly correlated with a lung injury score on days 7, 14 and 21 . In another study to document the activation of neutrophils, Chollet-Martin et al (60) observed that $\mathrm{P}$ selectins and beta2 integrins were present in greater abundance on the surface of neutrophils isolated from BAL fluid of patients with ARDS than of those with pneumonia.

In addition to these substances, other proinflammatory cytokines have been studied including tumour necrosis factor-alpha $(\mathrm{TNF} \alpha)$ and IL-1 $\beta$, both released very early in response to the insult triggering the inflammatory reaction, and are thought to play a prominent role, particularly in sepsis. Following a study by Suter et al (61) showing increased levels of TNF $\alpha$ and IL-1 $\beta$ in BAL fluids from ARDS patients, Pugin et al (62) reported in 1996 that $77 \%$ of patients meeting ARDS criteria had BAL fluids with proinflammatory activity that was maximal within the three first days of onset of the syndrome, and that was attributable mainly to IL-1 $\beta$ and not to TNF $\alpha$. It is interesting to link this observation with that of Goodman et al (59), who found a significant positive correlation between IL- $1 \beta$ levels in BAL fluids and mortality. Also noteworthy is the observation of Jacobs et al (63), who demonstrated that alveolar macrophages from patients with ARDS release much more IL- $1 \beta$ than alveolar macrophages from normal volunteers or from patients suffering from pneumonia. To complete the picture, Donnelly et al (64), recently showed that low levels of the IL-1 receptor antagonist (IL-1RA) in BAL fluids from ARDS patients correlated with a poor prognosis. All of the aforementioned data emphasize the role of IL-1 $\beta$ in the pathogenesis of ARDS. Interestingly, it has been recognized that the release of these cytokines (TNF $\alpha$, IL-1 $\beta$, IL-8) is controlled by a common pathway because Schwartz et al (65) showed that nuclear factor kappa $\mathrm{B}$, which is a major transcriptional regulator of these cytokines, is activated in alveolar macrophages from ARDS patients.

Consider molecules that can damage pulmonary architecture. Neutrophils are capable of releasing enzymes and oxygen radicals that result in membrane peroxydation. Myeloperoxidase and elastase are two neutrophil-derived enzymes whose levels in BAL fluids correlate with the extent of lung injury. However, much interest has been generated by metalloproteinases that can degrade basement membranes, whose destruction precludes the regeneration of a normal epithelium and leads to the proliferation of fibroblasts, culminating in the fibrosis described above. Torii et al (66) described two forms of metalloproteinase in BAL fluids, one originating from neutrophils, while Ricou et al (67) looked for the presence of a specific gelatinase and of its inhibitor, tissue inhibitor of metalloproteinase 1. In this last study, the authors distinguished rapidly resolving ARDS (lasting for less than five days) from long lasting ARDS (more than 15 days). In the latter, the gelatinase to inhibitor ratio remained high in BAL fluids.

What are mechanisms involved in the persistence of the inflammatory reaction? Is it the intensity or the duration of the original insult? Do nosocomial infections play a major role in perpetuating the inflammatory stimulus? In regard to these questions, Donnelly et al (68) recently reported the presence of the migration inhibitory factor produced by macrophages in BAL fluids, which favours the production of proinflammatory cytokines and inhibits the anti-inflammatory action of corticosteroids. The presence of sustained increased levels of these proinflammatory cytokines in fatal ARDS was indeed emphasized by Meduri et al (69). In keeping with this observation of an altered balance between proinflammatory and anti-inflammatory cytokines in ARDS, Donnelly et al (64) observed that low concentrations of anti-inflammatory cytokines such as IL-10 were linked closely to a poor prognosis.

Are these neutrophils always injurious and 'bad' cells in ARDS? There have been proposals to use granulocytecolony-stimulating factor (G-CSF) in infected non-neutropenic patients to improve organ recovery, prevent ARDS and increase survival (69). G-CSF dramatically enhances neutrophil recruitment and targets their defence capabilities to damaged organs, clearing debris and restoring function (69). Further support for this concept is the significant reduction in the incidence of ARDS in patients with community-acquired pneumonia receiving G-CSF $(70,71)$. Whether G-CSF can improve the course of evolving ARDS remains to be determined.

Many inflammatory mediators and antagonists have been shown to be involved in the pathogenesis of ARDS. Further studies, however, are required to identify which of these are key mediators, and to relate them to survival, allowing physicians to fine-tune the therapeutic approaches.

\section{THERAPEUTIC MODALITIES IN ARDS: REACHING A CONSENSUS AND BEING INNOVATIVE}

When evaluating treatments, it is important to recognize the trend towards decreased mortality from ARDS. Retrospective or prospective trials and studies, whether in North America or in Europe, show that the mortality of ARDS ranged from $40 \%$ to $60 \%$ in the past decade. This is generally lower than the dismal values reported in the late 1970s and early 1980s (72-74). This fall in mortality is not ascribed to 
any one specific change in therapy but rather is thought to reflect a general improvement in patient care. As the mortality rate of ARDS continues to decline, the demonstration of improved survival from any single therapeutic modality will prove more difficult, requiring studies with large numbers of patients in well designed multicentre trials, and probably added reliance on meta-analyses to identify their success or failure.

Mechanical ventilation: In the past decade, barotrauma has moved to the forefront of the complications of mechanical ventilation, possibly being "worse than the disease" according to some authors (75-78). In trying to move the understanding of this problem from bench to bedside, numerous investigators have ascertained that lung damage by barotrauma occurs in several animal models, and they have attempted to translate this into decreased morbidity and mortality in ARDS patients using a variety of 'lung protective' strategies (75-78). To date, however, unequivocal demonstration that lung damage can result from barotrauma secondary to mechanical ventilation in ARDS patients remains to be proven (77).

Animal studies have elegantly shown that high peak airway and transpulmonary pressures and volumes cause several side effects related to barotrauma, including a decrease in functional surfactant activity, increases in alveolocapillary barrier permeability, histological evidence of DAD, capillary stress failure from overdistention and alveolar shear stress from excessive changes in alveolar volume. Because, in many of these studies, peak inspiratory pressures leading to alveolar damage exceeded $40 \mathrm{~cm} \mathrm{H}_{2} \mathrm{O}$ and were obtained with variable tidal volumes ( 10 to $45 \mathrm{~mL} / \mathrm{kg}$ ) in the face of normal or reduced pulmonary parenchymal compliance, strategies to "protect; the lung were devised, recommending pressure and volume limitations as well as tolerance to any resulting hypercapnia. These strategies seemed particularly indicated because studies using CT scans showed that the lungs of patients with ARDS were densely infiltrated in their dependent portions (Figure 9), leaving 'baby lungs' to be recruited by mechanical ventilation and hinting that the markedly reduced volume would be overdistended by a conventional volume-controlled ventilation (79). Thus, using either volume or pressure-controlled mechanical ventilation, the current trend is to limit peak pressures to $40 \mathrm{~cm} \mathrm{H}_{2} \mathrm{O}$, plateau pressures to $35 \mathrm{~cm} \mathrm{H}_{2} \mathrm{O}$ and transpulmonary pressures to 30 $\mathrm{cm} \mathrm{H}_{2} \mathrm{O}$ by reducing tidal volumes to 5 to $10 \mathrm{~mL} / \mathrm{kg}$ and, in doing so, tolerating $\mathrm{PaCO}_{2}$ values in the 80 to $100 \mathrm{mmHg}$ range with $\mathrm{pH}$ values of 7.0 to 7.20 , with or without bicarbonate supplementation $(80,81)$. Contraindications to permissive hypercapnia include intracranial hypertension and cardiac disease. Permissive hypercapnia, however, may not be as innocuous as initially believed, in view of a recent study showing that morbidity seemed to parallel increasing $\mathrm{PaCO}_{2}$ values (82). In addition, care should be taken to ensure that increased intrathoracic pressures are not the result of decreased chest wall and abdominal compliance before recommending that peak or plateau pressures not to be exceeded (83). Following a review of the results of pressure

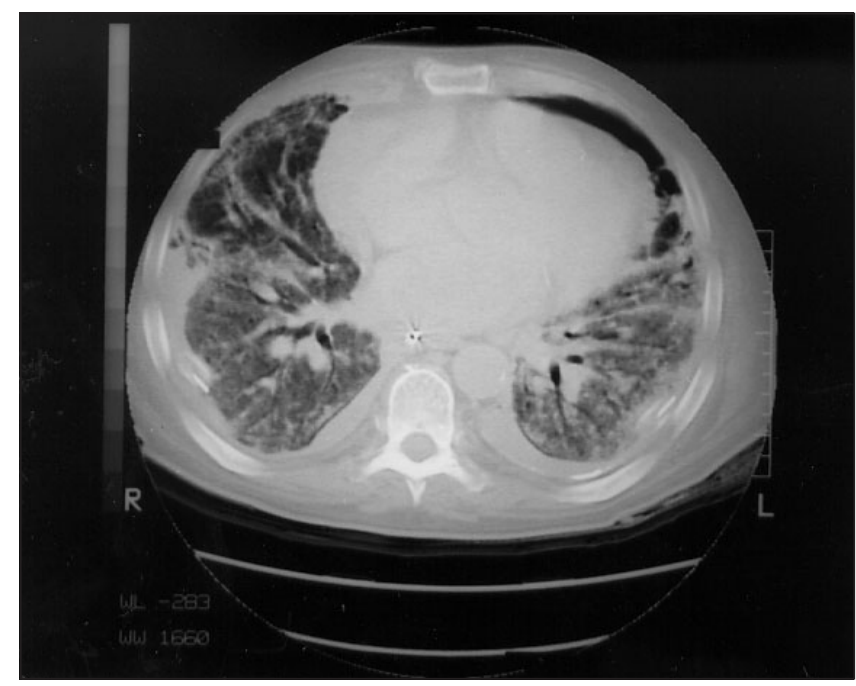

Figure 9) Heterogeneity and predominance of infiltrates in dependant regions in acute respiratory distress syndrome as assessed by computed tomography

limitation studies during mechanical ventilation in ARDS, it is not yet possible to prove a uniformly recognized decrease in mortality with this ventilatory mode $(24,82-84)$. Indeed, in these studies, dissimilar study designs with different goals can explain most of diverging results, and pressure limitation is no longer compared with volume-controlled ventilation (irrespective of resulting pressures) but with a variety of differing volume control groups.

Many of the basic ventilatory strategies in ARDS patients remain unchanged, being considered standard therapy without having been formally tested, and including the use of supplemental oxygen, PEEP and mechanical ventilation (9). It is still recommended that arterial oxygen saturation be maintained above $90 \%$ using the least amount of PEEP, titrating it to the lowest amount of pulmonary venous shunting, while maintaining an adequate oxygen transport or an optimal pressure-volume relationship $(9,85-87)$. Whether PEEP is titrated to maintain an adequate venous return and cardiac output or adjusted to the lower inflexion point of the pressurevolume curve, either method often yields values in a similar range (24). Overall, there is no consensus in the choice among volume-controlled ventilation in an assist-control mode instead of the intermittent-mandatory ventilation mode supplemented or not by pressure support; pressure support alone; and pressure control with or without inverse-ratio ventilation.

Finally, extracorporeal carbon dioxide removal is still considered an experimental technique. After showing an increase in survival without being compared with a control group, it failed to do so in a more rigorously designed study $(88,89)$. Retrospectively, these authors were promoting protective lung strategies by today's criteria, with the exception that carbon dioxide normalization was then considered a therapeutic goal in an era soon to be followed by permissive hypercapnia.

In summary, because maintaining oxygenation is the gold 
standard, the level of tolerable carbon dioxide and how to attain it, ie, whether by pressure- or volume-controlled ventilation, remain to be determined. Lung damage by barotrauma as a side effect of obtaining the desired oxygenation or carbon dioxide elimination is a feared iatrogenic consequence of an already severe form of acute lung injury.

Patient positioning: It has been shown by many groups using CT that lung infiltrates in ARDS are not uniformly distributed (90), the dependent portions of the lung being more densely infiltrated in supine patients, and these densities becoming redistributed in the prone position. Studies in animals have shown that prone positioning enabled the generation of sufficient transpulmonary pressures to reopen pathologically closed dorsal lung units, leading to better ventilation to perfusion $(\mathrm{V}: \mathrm{Q})$ ratios (91). Human studies have confirmed that the calculated compliance of the respiratory system is reduced in the prone position, that $\mathrm{V}: \mathrm{Q}$ matching is improved and that shunt decreases (92). These beneficial effects on oxygenation seem to last as long as patients are kept prone, but are lost when patients resume the supine position. Few randomized, controlled studies exist on the usefulness of the prone positioning and the prediction of which patients will respond; in addition, the question of whether nitric oxide or almitrine have added benefit remains unproven $(93,94)$. Although putting patients in the prone position can be cumbersome from a nursing point of view, some units have nonetheless use this technique simultaneously with extracorporeal carbon dioxide removal (74). A therapeutic algorithm of when and how to use this position, however, remains to be determined, although several groups already select it 'conventionally' early after the onset of ARDS.

Fluid management: Over the past 15 years, clinicians have gone from inducing hypovolemia, to the extent of requiring pressure support by using diuretics or continuous venovenous hemofiltration, to avoiding hypervolemia while maintaining an appropriate oxygen transport. To put it simply, it was hoped that by drying up the patients, the lung would also dry up. Later, it became evident that ARDS was the pulmonary manifestation of systemic endothelial injury with increased capillary permeability. In one frequently cited prospective study, survivors lost weight at 14 days while nonsurvivors gained weight, the average difference being $10 \mathrm{~kg}$ between the two groups (95). The easy conclusion was that excess fluid loss by diuretics might improve survival in ARDS patients by drying the lungs. This simplistic view was coloured by the idea that fluid requirements were probably larger in nonsurvivors, reflecting their greater degree of capillary leak and necessitating positive fluid balances to maintain adequate tissue perfusion. A retrospective study showed that, of two groups of patients treated with similar PEEP and oxygen concentrations, the ones with lower pulmonary capillary wedge pressures (PCWP) values (by only $6 \mathrm{mmHg}$ ) had better survival rates (96). In another study, negative fluid balance, whether determined by PCWP or extra-vascular lung water measurements, correlated with a shorter ICU stay but similar mortality (97). Pulmonary gas exchange has also been shown to be improved by continuous veno-venous hemofiltra- tion being added to diuretic therapy, even though it acts in a very different manner (98).

It is worth emphasizing that it is not appropriate to attempt to dry the lungs of patients who are very sick, with unstable hemodynamics and leaky capillaries, because they do not tolerate fluid restriction or fluid depletion. Moreover, inotropic or vasopressor support has not been shown to benefit these patients when trying to attain a negative fluid balance or to optimize oxygen transport or consumption (85-87). Any attentive clinician will recognize that patients tell him or her when they need their "tank to be filled", and subsequently, when fluid can be restricted or retrieved in various ways. The application of inappropriate generalized therapies that do not serve the individual patient must be avoided, and weight gain or loss should be used as a marker of disease severity and prognosis rather than as a stimulus to prescribe diuretics to those with ARDS.

Corticosteroids: According to older, apparently well established studies, corticosteroids were not recommended for the prophylaxis or early treatment of ARDS. Renewed interest in this therapeutic modality stems from their purported beneficial effect on mortality when administered in the late fibroproliferative phase; this application is being evaluated in a prospective multicentre trial (87). If, as reported by some European investigators (99), the development of pulmonary fibrosis accounts for high mortality rates in ARDS, it is possible that steroids may lower these rates by halting the inflammatory processes leading to fibrosis. Indeed, significant improvements in mortality from ARDS have been described with corticosteroids prescribed in the late fibroproliferative phase in observational and pilot studies, and recently in a randomized controlled trial (100-102). Patients in the observational group, in which favourable results were obtained, survived the initial insult, were free of infection before the use of steroids and showed active pulmonary inflammation by gallium scanning (100). Improvement in pulmonary function and survival rates, and a reduction in the secondary side effects and predictors of early or late response have been described in a pilot study of steroid treatment in the so-called late fibroproliferative phase of ARDS (101). Nevertheless, the appropriate indications and contraindications, dosing, timing, length of administration, and, most important, effectiveness of this therapy need to be established by the ongoing multicentre trial in late ARDS. Widespread use must await these trial results because of the obvious risks associated with this medication of yet unproven benefits.

Nitric oxide: Nitric oxide is a gas produced by most cells in different organ systems. The enzyme nitric oxide synthase (NOS) transforms L-arginine to nitric oxide and L-citrulline in the presence of two cosubstrates (oxygen and NADPH) and several cofactors (103). There are three main types of NOS: two constitutive forms, one present mainly in endothelial cells (eNOS isozyme) (104) and the other in neurones or muscular cells (nNOS isozyme) (105), both calciumdependent and producing picomoles of nitric oxide following chemical or physical stimulation. The third is inducible NOS (iNOS) (106), which can be induced in several cells follow- 
ing stimulation by several cytokines. iNOS is calcium independent and produces nitric oxide in the nanomolar range. Nitric oxide plays several important roles, with its main transduction signal being the activation of soluble guanylate cyclase producing cGMP.

Patients with severe ARDS are hypoxemic and exhibit pulmonary hypertension, usually in the setting of SIRS. A major and established activity of inhaled nitric oxide is that it acts as a pulmonary vasodilator, and has been shown to reduce pulmonary shunting in ARDS by improving ventilation to perfusion matching and oxygenation by selectively dilating that fraction of the pulmonary vasculature exposed to alveolar ventilation. Its effects on pulmonary artery pressures are nonetheless usually modest (107). Nitric oxide lacks the deleterious effects of systemically administered vasodilators, including hypotension, reducing hypoxic pulmonary vasoconstriction and further increasing shunting (107). An interesting and recent development is that nitric oxide may not be as locally selective as expected and seems to exhibit some extrapulmonary effects, especially on renal hemodynamics $(108,109)$.

Concentrations of inhaled nitric oxide used in clinical studies have varied greatly, from a few hundred parts/billion to several 10s of parts/million. To determine an 'ideal' concentration Troncy et al (110), in a prospective randomized study of medical and surgical patients with severe ARDS, measured the daily optimal inhaled nitric oxide concentrations, defined as the minimal concentration with the greatest effect on $\mathrm{PaO}_{2}$ (110). They found that an average of 5.5 parts/million was associated with an immediate effect on $\mathrm{PaO}_{2}$. There was a trend towards a reduction of mechanical ventilation length in the nitric oxide-treated group, but mortality rates were similar in both. About $30 \%$ of patients were 'responders' to inhaled nitric oxide treatment, with an increase in $\mathrm{PaO}_{2}$ not exceeding $20 \%$. These patients are commonly classified as nonresponders in the literature and are most often in sepsis. The prognosis was also worse in nonresponders to inhaled nitric oxide than in responders (110). The lack of an effect of inhaled nitric oxide on the mortality of ARDS in this study of Troncy et al (110) could be explained by a number of factors: the inclusion of too few patients, the fact that most patients (two of three) suffered from sepsisinduced ARDS, with ARDS being a systemic process, and that most of the patients died from multiple organ dysfunction syndrome (MODS), not from intractable respiratory failure, and the initial improvement in pulmonary function with inhaled nitric oxide being unsustained.

The usefulness of nitric oxide in ARDS may be to decrease requirements for PEEP and high oxygen concentrations, but an effect on the reduction of mortality in ARDS has yet to be demonstrated $(110,111)$. Recently, even the ability of inhaled nitric oxide to improve oxygenation in ARDS has been questioned in a randomized, controlled clinical trial (112). In Europe, nitric oxide is widely used by many groups, particularly in combination with almitrine bismesylate, an enhancer of hypoxic pulmonary vasoconstriction, or with the prone position, to improve oxygenation $(94,113)$. Phos- phodiesterase V inhibitors, such as zaprinast and dypyridamole which decrease cGMP catabolism, may also potentiate the effect of nitric oxide on pulmonary arterial pressure, oxygenation and inflammation. As with many other pharmacological approaches, nitric oxide does not seem to influence mortality, and it is still not known whether combining a variety of treatments will further improve outcome in ARDS.

Novel supportive therapy in ARDS: The limitations of ventilation approaches in improving oxygenation in ARDS have stimulated the development of new therapeutic strategies.

Surfactant replacement therapy: Surfactant replacement therapy has been proposed as a treatment because it is well known that ARDS is associated with surfactant dysfunction. Although there have been some encouraging results from initial clinical trials, a recent multicentre, randomized, placebo controlled study involving 725 patients with sepsisinduced ARDS did not demonstrate any impact of the artificial protein-free surfactant (Exosurf) on oxygenation, on duration of mechanical ventilation or on survival (114). Possible explanations for the negative results of this trial include inadequate drug delivery and the possibility that the artificial protein-free surfactants are not as efficacious as natural preparations. Hence, new studies are needed before a conclusion can be reached regarding the potential role of surfactants in the treatment of ARDS.

Liquid ventilation: Liquid ventilation is the most recently developed innovative approach to treat hypoxemia, using new organic molecules that are chemically stable, nonbiotransferable and virtually nontoxic (ie, perfluorocarbons). Perfluorocarbons are able to dissolve 17 times more oxygen than water. In several animal models of lung injury, liquid ventilation improves gas exchange compared with conventional ventilation (115). There are clinical reports on the safety and efficacy of partial liquid ventilation in adult (116) and pediatric (117) patients with ARDS, but much work is needed before this novel approach can be applied widely to the therapy of ARDS. Although innovative support treatments could ameliorate the outcome of ARDS patients, modification of the evolution of the disease is more likely to come from therapies aimed at the lung injury itself or at MODS, the major cause of death in ARDS.

Novel treatment of MODS: Over the past few years, it has become clear that the lung injury is only one manifestation of a more generalized process in which multiple organs are affected or at risk. MODS may be a complication of SIRS associated with sepsis, or of severe shock of noninfectious etiology. One hypothesis that may explain this generalized process is that there is inadequate tissue oxygen delivery in the early phase of ARDS. A recent consensus conference organized by the European Society of Intensive Care Medicine, the Société de Réanimation de Langue Française and the American Thoracic Society has provided guidelines for the optimization of oxygen delivery to tissues and the reduction of oxygen demand (118). However, it has been proposed that there is a pathological relationship between oxygen consumption and oxygen delivery $\left(\mathrm{DO}_{2}\right)$ in ARDS. To correct this problem, some groups have recommend increasing $\mathrm{DO}_{2}$ 
to supranormal levels, although the results of multiple clinical trials do not support this action at present (119).

The development of SIRS and MODS is also associated with an increased metabolic rate that alters body composition. Reversal of this process requires adequate nutritional support (120), and recent data seem to implicate certain nutrients in modulation of the inflammatory response. For example, there has been considerable interest in the potential role of glutamine in preventing epithelial atrophy and bacterial translocation in the gastrointestinal tract (121). However, data from the only one clinical trial to date do not support this strategy. Two other nutrients that have attracted some attention are arginine and omega- 3 polyunsaturated fatty acid, but data from at least two clinical studies that have evaluated their potential do not support their use at present $(122,123)$. In summary, although the prevention and control of MODS are important in the outcome of ARDS, no other effective treatments are available.

Novel pharmacological treatment of ARDS: Inflammatory mechanisms mediate ALI to produce the increased permeability characteristic of ARDS. Large numbers of neutrophils and monocytes are recruited to the distal lung airspaces, associated with the release of proinflammatory cytokines, oxygen radicals and proteases (124). Following up on these observations, numerous clinical trials have been conducted with the view to interrupting the inflammatory cascade in ALI. Because patients who develop ARDS following sepsis have the highest mortality, it seems logical to treat them either before they develop the lung injury or in the early phase. Unfortunately, to date, several clinical studies have failed to show clearly the benefits in septic patients treated with a variety of anti-inflammatory agents, including high doses of glucocorticoids, antiendotoxin monoclonal antibody therapy, anti-TNF therapy, anti-IL-1 therapy and prostaglandin modulatory therapy $(119,125)$.

$\mathrm{N}$-acetylcysteine, a molecule that acts as an oxygen-free radical scavenger and as a precursor for glutathione, an essential element of the antioxidant defense mechanism, has also been evaluated. This compound has been efficacious in some experimental $(119,126)$ and phase II clinical studies, and has been shown to produce a trend towards decreased nonpulmonary organ system dysfunction for the duration of assisted ventilation in ARDS patients. There is an ongoing prospective phase III trial with this agent.

The lack of success of these therapeutic modalities probably arises from the lack of knowledge of the detailed sequence of activation of the inflammatory mediators in the pathogenetic cascade. Thus, future therapy of lung injury will have to await a better understanding of the inflammatory response in ARDS.

Innovative treatment to accelerate the resolution of ARDS - The epithelium as a target: Until recently, most of the attention was focused on pulmonary endothelium dysfunction in ALI. It is now clear that the structure and function of the alveolar epithelium are also important determinants of lung injury. The alveolar epithelium is not only an important barrier to alveolar flooding but it is also the site of alveolar fluid reabsorption. Liquid reabsorption, requiring intact alveolar epithelial function, is an essential step in the resolution of ARDS and may have a significant impact on the prognosis of patients with this condition (16). Data in the literature indicate that if the alveolar epithelium can be restored to normal, alveolar fluid clearance will depend primarily on active sodium transport across it. The obvious clinical question is whether this process can be upregulated in ARDS patients.

In recent years, considerable effort has been devoted to understanding the mechanisms that regulate repair and remodelling of the injured lung as well as identifying mechanisms that upregulate edema resolution. New information indicates that hepatocyte growth factor and KGF are major mitogens and promigratory molecules for alveolar epithelial type II cells $(41,128)$. Recent studies suggest that pretreatment of animals with KGF before the inducing lung injury reduces the severity of the damage $(41,127-129)$. The mechanism of protection may be enhanced alveolar fluid transport from the increased number of alveolar type II cells in these animals $(41,130)$. Experimental data provide evidence that beta2-adrenergic stimulation also upregulates alveolar liquid clearance in normal and injured lungs, and that lung liquid clearance can be stimulated with dobutamine and dopamine (119). Thus, growth factors, vasoactive drugs and betaadrenergic agonists are potentially useful therapeutic modalities for patients with hydrostatic or increased permeability pulmonary edema.

\section{SUMMARY}

At the end of the 20th century, although ARDS is better understood, it remains a killer. Treatment of ARDS is mainly supportive because none of the new ventilatory strategies or pharmacological interventions has been shown in clinical trials to reduce morbidity or mortality. However, in recent years, the standards of supportive therapy seem to have led to a significant decrease in death due to ARDS. Further decreases in ARDS-related mortality should evolve from a better understanding of the mechanism of early inflammatory events in the lung injury and of the process of lung repair.

ACKNOWLEDGEMENTS: This work was supported in part by a grant of the Réseau en Santé Respiratoire du Fonds de Recherche en Santé du Québec FRSQ, of l'Association Pulmonaire du Québec and of the Medical Research Council of Canada (YB, grant MT10273). On behalf on the organizing staff of the meeting on ARDS held in October 1997, we thank other key speakers at the symposium for their expert contribution, Drs F Lemaire (Créteil), Dr S Renolleau, Paris and Dr P Charron, Sherbrooke. Drs Berthiaume and Lesur are chercheurs-boursiers cliniciens of le Fonds de Recherche en Santé du Québec Fonds de Recherche en Santé du Québec (FRSQ).

\section{REFERENCES}

1. Ashbaugh DG, Bigelow DB, Petty TL, et al. Acute respiratory distress in adults. Lancet 1967;ii:319-23.

2. Petty TL. The acute respiratory distress syndrome. Historic perspective. Chest 1994;105(Suppl 3):44s-7s.

3. Murray IF. The adult respiratory distress syndrome (may it rest in peace). Am Rev Respir Dis 1975;111:716-8. 
4. Petty TL. The adult respiratory distress syndrome (confessions of a "lumper"). Am Rev Respir Dis 1975;111:711-5.

5. Murray JF, Matthay MA, Luce JM, Flick MR. An expanded definition of the adult respiratory distress syndrome. Am Rev Respir Dis 1988; 138:720-3.

6. Schuster DP. What is acute lung injury? What is ARDS? Chest 1995;107:1721-6.

7. Thomsen GE, Morris AH. Incidence of the adult respiratory distress syndrome in the state of Utah. Am J Respir Crit Care Med 1995;152:965-71.

8. Krafft P, Fridrich P, Pernestofer T, et al. The acute respiratory distress syndrome: definitions, severity and clinical outcome. An analysis of 101 clinical investigations. Intensive Care Med 1996;22:519-29.

9. Bernard GR, Artigas A Brigham KL, et al. The American-European consensus conference on ARDS. Definitions, mechanisms, relevant outcomes, and clinical trial coordination. Am J Respir Crit Care Med 1994;149:818-24.

10. Artigas A, Bernard GR, Carlet J, et al. The American-European consensus conference on ARDS. Definitions, mechanisms, relevant outcomes, and clinical trial coordination. Am J Respir Crit Care Med 1998;157:1332-47.

11. Knaus WA. The ongoing mystery of ARDS. Intensive Care Med 1996;22:517-8.

12. Weibel ER, Taylor CR. Design and structure of the human lung. In: Fishman AP, ed. Pulmonary Diseases and Disorders, vol 1, 2nd edn. New York: McGraw-Hill, 1988:11-60.

13. Bachofen M, Weibel ER. Alteration of the gas exchange apparatus in adult respiratory insufficiency associated with septicemia. Am Rev Respir Dis 1977;116:589-615.

14. Matthay MA, Landolt CC, Staub NC. Differential liquid and protein clearance from the alveoli of anesthetized sheep. J Appl Physiol 1982;53:96-104

15. Sloane PI, Gee MH, Gottlieb IE, et al. A multicenter registry of patients with acute respiratory syndrome. Physiology and outcome. Am Rev Respir Dis 1992;146:419-26.

16. Matthay MA, Wiener-Kronish JP. Intact epithelial barrier function is critical for the resolution of alveolar edema in humans. Am Rev Respir Dis 1990;142:1250-7.

17. Gattinoni L, Bombino M, Lissoni A, et al. Lung structure and function in different stages of severe adult respiratory distress syndrome. JAMA 1994;271:1772-9.

18. Ghio AJ, Elliott CG, Crapo RO, Berlin SL, Jensen RL. Impairment after adult respiratory distress syndrome. An evaluation based on American Thoracic Society recommendations. Am Rev Respir Dis 1989;139:1158-62.

19. Hudson LD. What happens to survivors of the adult respiratory distress syndrome? Chest 1994;105(Suppl 3):123s-6s.

20. Gowda MS, Klocke RA. Variability of indices of hypoxemia in adult respiratory distress syndrome. Crit Care Med 1997;25:41-5.

21. Gould MK, Ruoss SI, Rizk NW, Doyle RL, Raffin TA. Indices of hypoxemia in patients with acute respiratory distress syndrome: reliability, validity, and clinical usefulness. Crit Care Med 1997;25:6-8

22. Fowler AA, Hamman RF, Zerbe GO, Benson KN, Myers TM. Adult respiratory distress syndrome. Prognosis after onset. Am Rev Respir Dis $1985 ; 132: 472-8$

23. Ferring M, Vincent JL. Is outcome from ARDS related to the severity of respiratory failure? Eur Respir J 1997;10:1297-300.

24. Amato MB, Barbas CS, Medeiros DM, et al. Effect of a protective-ventilation strategy on mortality in the acute respiratory distress syndrome. N Engl J Med 1998;338:347-54.

25. Montaner JS, Lawson LM, Levitt N, et al. Corticosteroids prevent early deterioration in patients with moderately severe Pneumocystis carinii pneumonia and the acquired respiratory distress syndrome. Ann Intern Med 1990;113:14-20.

26. Corrin B. Diffuse alveolar damage. In: Haslett C, Evans TW, eds. ARDS. Acute Respiratory Distress in Adults. London: Chapman \& Hall Medical, 1996:37-46.

27. Lamy M, Fallat RJ, Koeniger E, et al. Pathologic features and mechanisms of hypoxemia in adult respiratory distress syndrome. Am Rev Respir Dis 1976;114:267-84.

28. Pratt PC, Vollmer RT, Shelburne JD, Crapo JD. Pulmonary morphology in a multihospital collaborative extracorporeal membrane oxygenation project. I. Light microscopy. Am J Pathol 1979;95:191-214.

29. Tomashefski JF, Davies P, Boggis C, Greene R, Zapol WM, Reid LM.
The pulmonary vascular lesions of the adult respiratory distress syndrome. Am J Pathol 1983;112:112-26.

30. Vassilyadi M, Michel RP. Pattern of fluid accumulation in $\mathrm{NO}_{2}$-induced pulmonary edema in dogs. A morphometric study. Am J Pathol 1988;130:10-21.

31. Iancu DM, Zwikler MP, Michel RP. Distribution of alveolar edema in ventilated and unventilated canine lung lobes. Invest Radiol 1996;31:423-32.

32. Malo J, Ali J, Wood LDH. How does positive end-expiratory pressure reduce intrapulmonary shunt in canine pulmonary edema? J Appl Physiol 1984;57:1002-10.

33. Gattinoni L, D’Andrea L, Pelosi P. Regional effects and mechanism of positive end-expiratory pressure in early adult respiratory distress syndrome. JAMA 1993;269:2122-7.

34. Dreyfuss D, Basset G, Soler P, Saumon G. Intermittent positive-pressure hyperventilation with high inflation pressures produces pulmonary microvascular injury in rats. Am Rev Respir Dis 1985;132:880-4.

35. Martinez-Hernandez A, Amenta PS. The basement membrane in pathology. Lab Invest 1983;48:656-77.

36. Vracko R. Significance of basal lamina for regeneration of injured lung. Virchows Arch A Pathol Anat Histopathol 1972;355:264-74.

37. Matsubara O, Tamura A, Ohdama S, Mark EJ. Alveolar basement membrane breaks down in diffuse alveolar damage: an immunohistochemical study. Pathol Int 1995;45:473-82.

38. Adamson IYR, Hedgecock C, Bowden DH. Epithelial cell-fibroblast interactions in lung injury and repair. Am J Pathol 1990;137:385-92.

39. Adamson IYR, Young L, Bowden DH. Relationship of alveolar injury and repair to the induction of pulmonary fibrosis. Am J Pathol 1988; 130:377-83.

40. Adamson IYR, Bowden DH. The type 2 cell as progenitor of alveolar epithelial regeneration. A cytodynamic study in mice after exposure to oxygen. Lab Invest 1974;30:35-42.

41. Berthiaume Y, Lesur O, Dagenais A. Treatment of the adult respiratory distress syndrome: plea for rescue treatment of the alveolar epithelium. Thorax 1999;54:150-60.

42. Kawanami O, Ferrans VJ, Crystal RG. Structure of alveolar epithelial cells in patients with fibrotic lung disorders. Lab Invest 1982;46:39-53.

43. Marinelli WA, Henke CA, Harmon KR, Hertz MI, Bitterman PB. Mechanisms of alveolar fibrosis after acute lung injury. Clin Chest Med 1990;11:657-72.

44. Villar J, Slutsky AS. The incidence of the adult respiratory distress syndrome. Am Rev Respir Dis 1989;140:814-6.

45. American Lung Program. Respiratory Diseases. Task force report on problems, research approaches, needs. The lung program. National Heart and Lung Institute [DHEW Publication No (NIH) 73-432]. Washington, DC: US Government Printing Office, 1972:165-85.

46. Hudson LD, Martin TR. Predicting ARDS: problems and prospects. Lancet 1997;349:1783.

47. Panos RJ. Cytokines and alveolar type II cells. In: Kelley J, ed. Cytokines of the Lung. New-York: Marcel Dekker Inc, 1993:417-56.

48. Khalil N, O'Connor RN, Flanders KC, Shing W, Whitman CI. Regulation of type II alveolar epithelial cell proliferation by transforming growth factor- $\beta$ during bleomycin-induced lung injury in rats. Am J Physiol 1994;267:L498-507.

49. Snyder LS, Hertz MI, Peterson MS, et al. Acute lung injury: pathogenesis of intraalveolar fibrosis. J Clin Invest 1991;88:663-73.

50. Pierce GF, Mustoe TA. Pharmacologic enhancement. Ann Rev Med 1995;46:467-81.

51. Lesur O, Arsalane, Bérard J, et al. Functional IL-2 receptors are expressed by rat lung type II epithelial cells. Am J Physiol 1997;273:L495-503.

52. Bulfone-Paus S, Ungureanu D, Phol T, et al. Interleukin-15 protects from lethal apoptosis in vivo. Nature Med 1997;3:124-8.

53. Weiland JE, Davis WB, Holter JF, Mohammed JR, Dorinsky PM, Gadek JE. Lung neutrophils in the adult respiratory distress syndrome. Am Rev Respir Dis 1986;133:218-25.

54. Fowler AA, Hyers TM, Fisher BJ, Beckard DE, Centor RM, Webster RO. The adult respiratory distress syndrome. Cell populations and soluble mediators in the air spaces of patients at high risk. Am Rev Respir Dis 1987;136:1225-31.

55. Steinberg K, Milberg J, Martin T, Maunder R, Cockrill B, Hudson L. Evolution of bronchoalveolar cell populations in the adult respiratory distress syndrome. Am J Respir Crit Care Med 1994;150:113-22. 
56. Miller E, Cohen A, Nagao S, et al. Elevated levels of NAP-1/IL-8 are present in the air spaces of patients with ARDS and are associated with increased mortality. Am Rev Respir Dis 1992;146:427-32.

57. Jorens P, Van Damme J, De Backer W, et al. IL-8 in the bronchoalveolar lavage fluid from patients with the ARDS and patients at risk for ARDS. Cytokine 1992;4:592-7.

58. Miller EJ, Cohen AB, Matthay MA. Increased interleukin-8 concentrations in the pulmonary edema fluid of patients with acute respiratory distress syndrome from sepsis. Crit Care Med 1996;24:1448-54.

59. Goodman RB, Strieter RM, Martin DP, et al. Inflammatory cytokines in patients with persistence of the acute respiratory distress syndrome. Am J Respir Crit Care Med 1996;154:602-11.

60. Chollet-Martin S, Jourdain B, Gibert C, Elbim C, Chastre J, Gagerot-Pocidalo M. Interaction between neutrophils and cytokines in blood and alveolar spaces during ARDS. Am J Respir Crit Care Med 1996;153:594-601.

61. Suter PM, Suter S, Girardin E, Roux-Lombard P, Grau G, Dayer JM. High bronchoalveolar levels of tumor necrosis factor and its inhibitors, interleukin-1, interferon, and elastase, in patients with ARDS after trauma shock or sepsis. Am Rev Respir Dis 1992;145:1016-22.

62. Pugin J, Ricou B, Steinberg K, Suter P, Martin T. Pro-inflammatory activity in bronchoalveolar lavage fluids from patients with ARDS, a prominent role for IL-1. Am J Respir Crit Care Med 1996;153:1850-6.

63. Jacobs R, Tabir D, Burks W, Campbell G. Elevated IL-1 release by human alveolar macrophages during the ARDS. Am Rev Respir Dis 1989;140:1686-92.

64. Donnelly SC, Strieter RM, Reid PT, et al. The association between mortality rates and decreased concentrations of IL-10 and IL-1ra in the lung fluids of patients with the ARDS. Ann Intern Med 1996;125:191-6.

65. Schwartz M, Moore E, Moore F, et al. Nuclear factor-kB is activated in alveolar macrophages from patients with acute respiratory distress syndrome. Crit Care Med 1996;24:1285-92.

66. Torii K, Iida K, Miyazaki Y, et al. Higher concentrations of matrix metalloproteinases in bronchoalveolar lavage fluid of patients with adult respiratory distress syndrome. Am J Respir Crit Care Med 1997;155:43-6.

67. Ricou B, Nicad L, Lacraz S, Welgur H, Suter P, Dayer J. Matrix metalloproteinases and TIMP in acute respiratory distress syndrome. Am J Respir Crit Care Med 1996;154:346-52.

68. Donnelly S, Haslett C, Reid P, et al. Regulatory role for macrophage migration inhibitory factor in acute respiratory distress syndrome. Nature Med 1997;3:320-3.

69. Meduri GV, Kohler G, Headley S, Tolley E, Stentz F, Poslethwaite A Inflammatory cytokines in the BAL of patients with ARDS. Chest 1995;108:1303-14.

70. Nelson S. Granulocyte colony-stimulating factor in systemic and pulmonary infections. In: Nelson S, ed. Cytokines and Pulmonary Infection. Part II: The Role of Cytokines in Systemic and Pulmonary Medicine. Washington: American Thoracic Society, 1997:29-39.

71. Nelson S. Modifying the host response to infection with granulocyte colony-stimulating factor. In: Nelson S, ed. Cytokines and Pulmonary Infection. Part I: Host-pathogen Interactions in Pulmonary Infections. Washington: American Thoracic Society, 1997:11-7.

72. Milberg JA, Davis DR, Steinberg KP, et al. Improved survival of patients with acute respiratory distress syndrome (ARDS): 1983-1993. JAMA 1995;273:306-9.

73. Lewandowski K, Metz J, Deutschmann C, et al. Incidence, severity, and mortality of acute respiratory failure in Berlin, Germany. Am J Respir Crit Care Med 1995;151:1121-5.

74. Rich PB, Awad SS, Kolla S, et al. An approach to the treatment of severe adult respiratory failure. J Crit Care 1998;13:26-36.

75. Tsuno K, Miura K, Takeya M, et al. Histopathologic pulmonary changes from mechanical ventilation at high peak airway pressures. Am Rev Respir Dis 1991;143:1115-20.

76. Dreyfuss D, Saumon G. Role of tidal volume, FRC, and end-inspiratory volume in the development of pulmonary edema following mechanical ventilation. Am Rev Respir Dis 1993;148:1194-203.

77. Hickling KG. Ventilatory management of ARDS: can it affect the outcome? Intensive Care Med 1990;16:219-26.

78. Marini JJ, Kelsen SG. Re-targeting ventilatory objectives in adult respiratory distress syndrome. Am Rev Respir Dis 1992;146:2-3.

79. Gattinoni L, Pesenti A, Avalli L, et al. Pressure-volume curve of the total respiratory system in acute respiratory failure. A computed tomographic study. Am Rev Respir Dis 1987;136:730-6.

80. Feihl F, Perret C. Permissive hypercapnia: how permissive should we be? Am J Respir Crit Care Med 1994;150:1722-37.

81. Tuxen DV. Permissive hypercapnic ventilation. Am J Respir Crit Care Med 1994;150:870-4

82. Stewart TE, Meade MO, Cook DJ, et al. Evaluation of a ventilation strategy to prevent barotrauma in patient at high risk of acute respiratory distress syndrome. N Engl J Med 1998;338:355-61.

83. Stewart TE, Slutsky AS. Current status of pressure limitation during mechanical ventilation for ARDS. Intensive Care World 1997;14:73-6

84. Hickling KG, Walsh J, Henderson S. Low mortality rate in adult respiratory distress syndrome using low-volume, pressure-limited ventilation with permissive hypercapnia: a prospective study. Crit Care Med 1994;22:1568-78.

85. Kollef MH, Schuster DP. The acute respiratory distress syndrome. N Engl J Med 1995;332:27-36.

86. Hudson LD. New therapies for ARDS. Chest 1995;108:79S-91S

87. Luce JM. Acute lung injury and the acute respiratory distress syndrome. Crit Care Med 1998;26:369-76.

88. Gattinoni L, Pesenti A, Masheroni D, et al. Low-frequency positive pressure ventilation with extracorporeal $\mathrm{CO}_{2}$ removal in severe acute respiratory failure. JAMA 1986;256:881-6.

89. Morris AH, Wallace J, Morlove R, et al. Randomized clinical trial of pressure-controlled inverse ratio ventilation and extracorporeal $\mathrm{CO}_{2}$ removal for adult respiratory distress syndrome. Am J Respir Crit Care Med 1994;149:295-305.

90. Gattinoni L, Pelosi P, Vitale G, et al. Body position changes redistribute lung computed-tomographic density in patient with acute respiratory failure. Anesthesiology 1991;74:15-23.

91. Lamm WJE, Graham MM, Albert RK. Mechanism by which the prone position improves oxygenation in acute lung injury. Am J Respir Crit Care Med 1994;150:184-93.

92. Pappert D, Rossaint R, Slama K, et al. Influence of positioning on ventilation-perfusion relationships in severe adult respiratory distress syndrome. Chest 1994;106:1511-6.

93. Levy B, Bollaert PE, Bauer P, et al. Therapeutic optimization including inhaled nitric oxide in adult respiratory distress syndrome in a polyvalent intensive care unit. J Trauma 1995;38:370-4.

94. Guinard N, Beloucif S, Gatecel C, et al. Interest of a therapeutic optimization strategy in severe ARDS. Chest 1997;111:1000-7.

95. Simmons RS, Berdine GG, Seidenfeld JJ, et al. Fluid balance and the adult respiratory distress syndrome. Am Rev Respir Dis 1987; 135:924-9.

96. Humphrey H, Hall J, Sznajder I, Silverstein M, Wood L. Improved survival in ARDS patient associated with a reduction in pulmonary capillary wedge pressure. Chest 1990;97:1176-80.

97. Mitchell JP, Schuller D, Calandrino FS, et al. Improved outcome based on fluid management in critically ill patients requiring pulmonary artery catheterization. Am Rev Respir Dis 1992;145:990-8.

98. Garzia F, Todor R, Scalea T. Continuous arteriovenous hemofiltration countercurrent dialysis (CAVH-D) in acute respiratory failure (ARDS). J Trauma 1991;31:1277-85.

99. Martin C, Papazian L, Payen MJ, et al. Pulmonary fibrosis correlates with outcome in adult respiratory distress syndrome. Chest 1995;107:196-200

100. Hooper RG, Kearl RA. Established ARDS treated with a sustained course of adreno cortical steroids. Chest 1990;97:138-43.

101. Meduri GV, Chinn AJ, Leeper KV. Corticosteroid rescue treatment of progressive fibro proliferation in late ARDS: patterns of response and predictors of outcome. Chest 1994;105:1516-27.

102. Meduri GU, Headley AS, Golden E, et al. Effects of prolonged methylprednisolone therapy in unresolving acute respiratory distress syndrome. JAMA 1998;280:159-65.

103. Knowles RG, Moncada S. Nitric oxide synthases in mammals. Biochem J 1994;298:249-58.

104. Michel T, Feron O. Nitric oxide synthases: which, where, how, and why? J Clin Invest 1997; 100:2146-52.

105. Christopherson KS, Bredt DS. Nitric oxide in excitable tissues: physiological roles and disease. J Clin Invest 1997;100:2424-9.

106. Nathan C. Inducible nitric oxide synthase: what difference does it make? J Clin Invest 1997;100:2417-23.

107. Rossaint R, Falke KJ, Lopez F, et al. Inhaled nitric oxide for the adult respiratory distress syndrome. N Engl J Med 1993;328:399-405.

108. Troncy E, Francoeur M, Salazkin I, Vinay P, Blaise GA. Systemic 
effect of inhaled nitric oxide: modification of renal hemodynamics in pigs. In: Moncada S, Stamler S, Gross G, Higgs AE, eds. The Biology of Nitric Oxide, part 5. London: Portland Press Ltd, 1996:319.

109. Troncy E, Francoeur M, Salazkin I, et al. Extra-pulmonary effects of inhaled nitric oxide in swine with or without phenylephrine. Br J Anaesth 1997;79:631-40.

110. Troncy E, Collet JP, Shapiro S, et al. Inhaled nitric oxide in acute respiratory distress syndrome. A pilot randomized controlled study. Am J Respir Crit Care Med 1998;157:1483-8

111. Dillinger RP, Zimmerman JL, Taylor RW, et al. Effects of inhaled nitric oxide in patients with acute respiratory distress syndrome: results of a randomized phase II trial. Crit Care Med 1998;26:15-23.

112. Michael JR, Barton RG, Saffle JR, et al. Inhaled nitric oxide versus conventional therapy. Effect on oxygenation in ARDS. Am J Respir Crit Care Med 1998;157:1372-80.

113. Wysocki M, Delclaux C, Roupie E, et al. Additive effect on gas exchange of inhaled nitric oxide and intravenous almitrine bismesylate in the adult respiratory distress syndrome. Intensive Care Med 1994;20:254-9.

114. Anzueto A, Baughman RP, Guntupalli KK, et al. Aerosolized surfactant in adults with sepsis-induced acute respiratory distress syndrome. Exosurf Acute Respiratory Distress Syndrome Sepsis Study Group. N Engl J Med 1996;334:1417-21.

115. Hernan LJ, Fuhrman BP, Kaiser RE, et al. Perfluorocarbon-associated gas exchange in normal and acid-injured large sheep. Crit Care Med 1996;24:475-81.

116. Hirschl RB, Pranikoff T, Wise C, et al. Initial experience with partial liquid ventilation in adult patients with the acute respiratory distress syndrome. JAMA 1996;275:383-9.

117. Gauger PG, Pranikoff T, Schreiner RJ, Moler FW, Hirschl RB. Initial experience with partial liquid ventilation in pediatric patients with the acute respiratory distress syndrome. Crit Care Med 1996;24:16-22.

118. Third European Consensus Conference in Intensive Care Medicine. Tissue hypoxia: How to detect, how to correct, how to prevent. Société de Réanimation de Langue Française. The American Thoracic Society. European Society of Intensive Care Medicine. Am J Respir Crit Care Med 1996;154:1573-8.
119. Berthiaume Y, Ware LB, Matthay MA. Treatment of acute pulmonary edema and the adult respiratory distress syndrome. In: Matthay MA, Ingbar DH, eds. Pulmonary Edema. New York: Marcel Dekker, 1998:575-631.

120. O'Leary MJ, Coakley JH. Nutrition and immunonutrition. Br J Anaesth 1996;77:118-27

121. Thompson WA, Lowry SF. Effect of nutrition on inflammatory mediators. In: Zaloga GP, ed. Nutrition in Critical Care. St Louis: Mosby, 1994:505-23.

122. Bower RH, Cerra FB, Bershadsky B, et al. Early enteral administration of a formula (Impact) supplemented with arginine, nucleotides, and fish oil in intensive care unit patients: Results of a multicenter, prospective, randomized, clinical trial. Crit Care Med 1995;23:436-49.

123. Garrel DR, Razi M, Larivière F, et al. Improved clinical status and length of care with low-fat nutrition support in burn patients. JPEN J Parenter Enteral Nutr 1995;19:482-91.

124. Pittet JF, Mackersie RC, Martin TR, Matthay MA. Biological markers of acute lung injury: prognostic and pathogenetic significance. Am J Respir Crit Care Med 1997;155:1187-205.

125. Bernard G. Sepsis trials. Intersection of investigation, regulation, funding and practice. Am J Respir Crit Care Med 1995;152:4-10

126. Bernard GR, Lucht WD, Niedermeyer ME, Snapper JR, Ogletree ML, Brigham KL. Effect of N-acetylcysteine on the pulmonary response to endotoxin in awake sheep and upon in vitro granulocyte function. J Clin Invest 1984;73:1772-84.

127. Ulich T, Yi E, Longmuir K, et al. Keratinocyte growth factor is a growth factor for type II pneumocytes in vivo. J Clin Invest 1994;93:1298-306.

128. Panos RJ, Bak PM, Simonet WS, Rubin JS, Smith LJ. Intratracheal instillation of keratinocyte growth factor decreases hyperoxia-induced mortality in rats. J Clin Invest 1995;96:2026-33.

129. Mason CM, Guery BP, Summer WR, Nelson S. Keratinocyte growth factor attenuates lung leak induced by a-naphthylthiourea in rats. Crit Care Med 1996;24:925-31.

130. Guery BP, Mason CM, Dobard EP, Beaucaire G, Summer WR, Nelson S. Keratinocyte growth factor increases transalveolar sodium reabsorption in normal and injured rat lungs. Am J Respir Crit Care Med 1997;155:1777-84. 


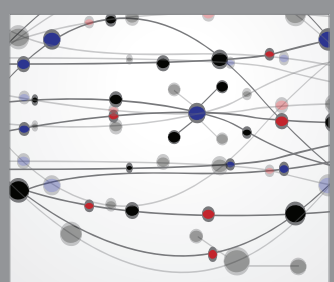

The Scientific World Journal
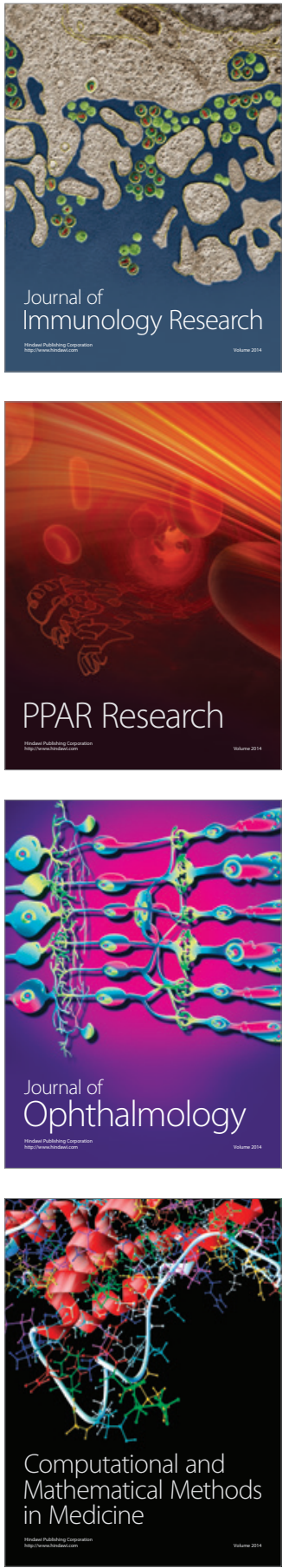

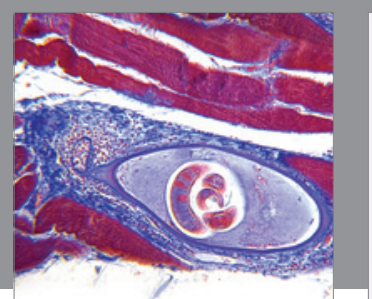

Gastroenterology Research and Practice

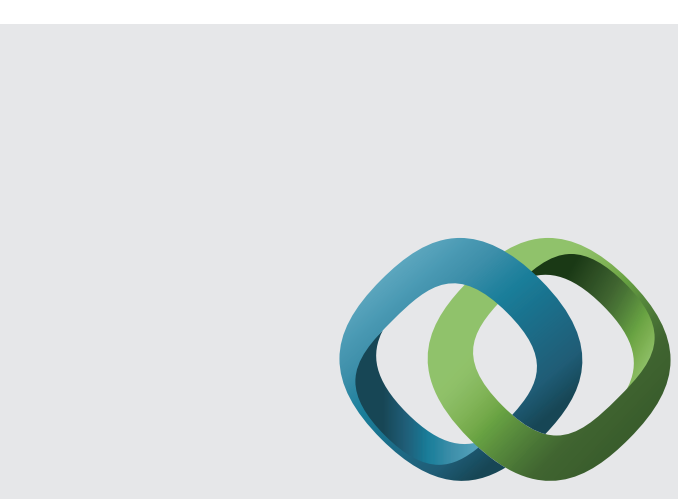

\section{Hindawi}

Submit your manuscripts at

http://www.hindawi.com
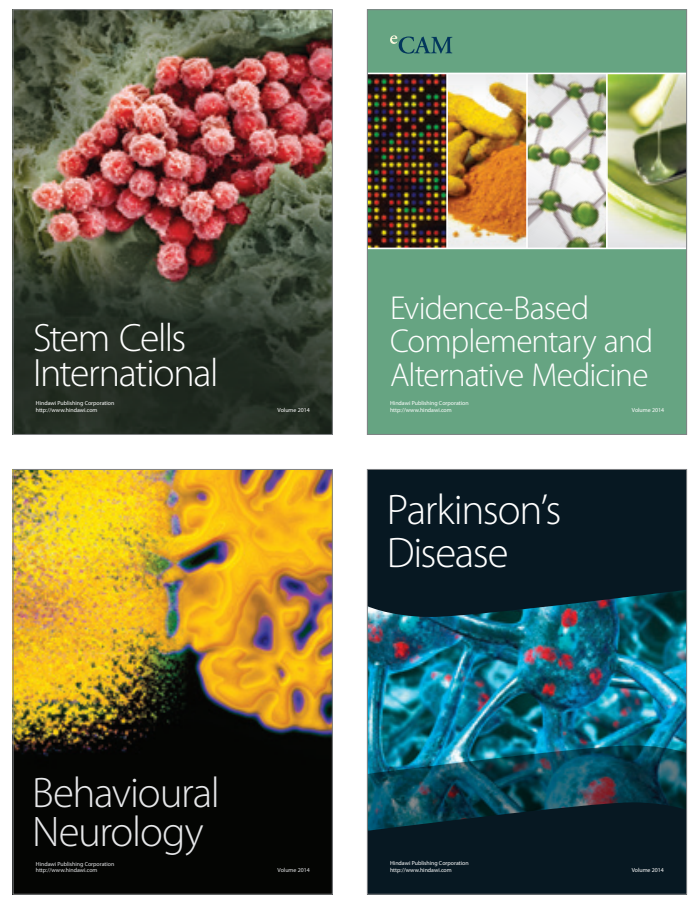
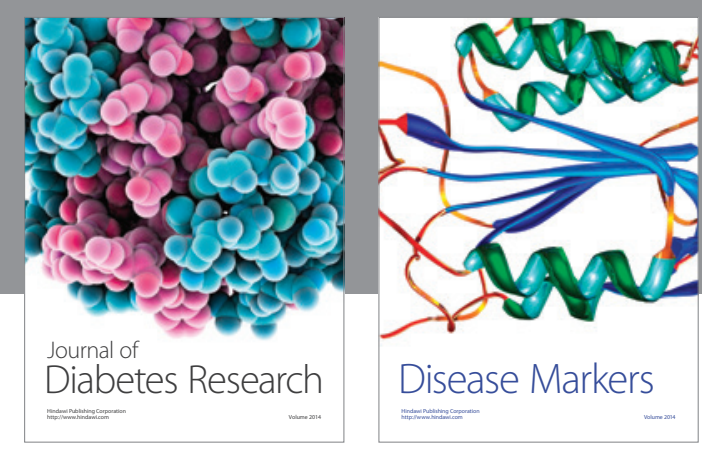

Disease Markers
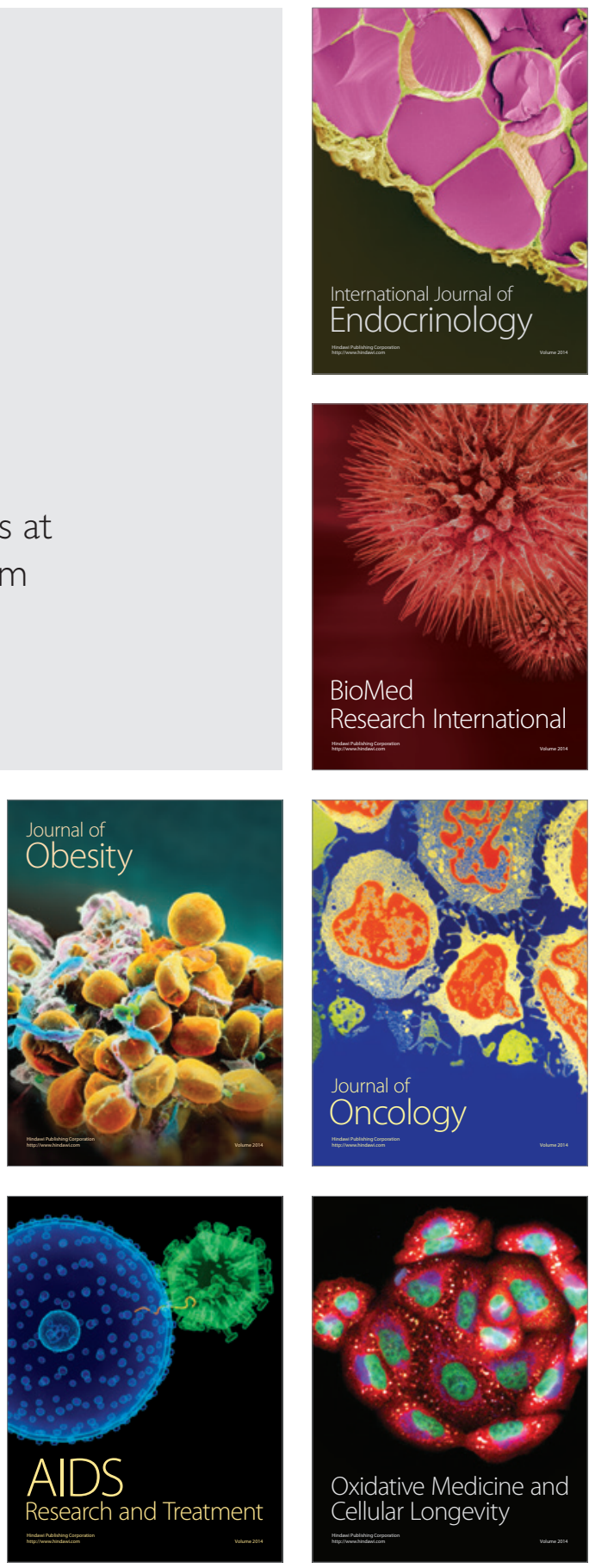